\title{
Field observations of shear waves in the surf zone
}

\author{
T. James Noyes and R. T. Guza \\ Integrative Oceanography Division, Scripps Institution of Oceanography, La Jolla, California, USA
}

\section{Steve Elgar}

Woods Hole Oceanographic Institution, Woods Hole, Massachusetts, USA

T. H. C. Herbers

Naval Postgraduate School, Monterey, California, USA

Received 23 December 2002; revised 23 August 2003; accepted 14 October 2003; published 31 January 2004.

[1] Alongshore propagating meanders of the mean alongshore current in the surf zone called shear waves have periods of a few minutes and wavelengths of a few hundred meters. Here shear wave properties are estimated with arrays of current meters deployed for 4 months within $300 \mathrm{~m}$ of the shoreline of a sandy beach. Shear wave velocity fluctuations are approximately horizontally isotropic, with root mean square values between 10 and $40 \%$ of the mean (3-hour-averaged) alongshore current $V$. Cross-shore variations of the time-averaged shear wave momentum flux are consistent with shear wave energy generation close to shore where the breaking wave-driven mean alongshore current $V$ and current shear $V_{x}$ are strong and with shear wave energy dissipation and transfer back to the mean flow farther offshore where $V$ and $V_{x}$ are weak. In case studies where $V$ is a narrow jet near the shoreline the observed strong decay of shear wave energy levels seaward of the jet, and the cross-shore and alongshore structure of shear waves within the jet, are similar to predictions based on the linearly unstable modes of the observed $V$. Shear wave energy levels also are high in a marginally unstable case with a strong, but weakly sheared, $V$. INDEX TERMS: 4546 Oceanography: Physical: Nearshore processes; 4568 Oceanography: Physical: Turbulence, diffusion, and mixing processes; KEYWORDS: shear waves, longshore currents, surf zone

Citation: Noyes, T. J., R. T. Guza, S. Elgar, and T. H. C. Herbers (2004), Field observations of shear waves in the surf zone, J. Geophys. Res., 109, C01031, doi:10.1029/2002JC001761.

\section{Introduction}

[2] Shear waves, velocity fluctuations with periods of a few minutes and wavelengths of a few hundred meters, are believed to result from shear instabilities of surfzone mean alongshore currents. The linearly unstable modes are approximately nondispersive, with small pressure fluctuations, and alongshore phase speeds that are less than the maximum mean alongshore current and much less than the phase speeds of surface gravity waves of the same frequency [Bowen and Holman, 1989], consistent with observations [Oltman-Shay et al., 1989].

[3] Howd et al. [1991] estimated the variance of shear wave velocity fluctuations in the trough of a nearshore sandbar by integrating alongshore wave number-frequency spectra $E(k, f)$ of both horizontal velocity components over the region of $k-f$ space that is outside the theoretical range of gravity waves. Over a 10-day period, shear wave velocity variance was correlated with both the observed mean

Copyright 2004 by the American Geophysical Union. 0148-0227/04/2002JC001761\$09.00 alongshore current $V$ and the (modeled) maximum crossshore current shear $V_{x}$, and contributed as much as half of the total velocity variance in the infragravity frequency band (with the remainder at the $(k, f)$ of gravity waves). Shear waves also may contribute to sediment suspension [Miles et al., 2000].

[4] Dodd et al. [1992] extended the shear wave stability analysis to include dissipation by bottom drag and the arbitrary cross-shore variation of $V(x)$ and depth $h(x)$, and obtained good agreement with phase speeds observed in the trough of a barred beach. Smaller bottom drag [Dodd et al., 1992] or increased shear on the shoreward side of the mean current jet [Baquerizo et al., 2001] were required to obtain unstable modes for a case study on a planar beach.

[5] Numerical models based on the unsteady nonlinear shallow water equations have been used to study the finite amplitude evolution of shear instabilities. In the region of strongest $V(x)$, both weakly and strongly nonlinear shear waves are nondispersive with phase speeds similar to the speeds of the linearly unstable modes [Allen et al., 1996; Slinn et al., 1998]. The observed shear wave energy levels are similar to numerical simulations of strongly nonlinear 


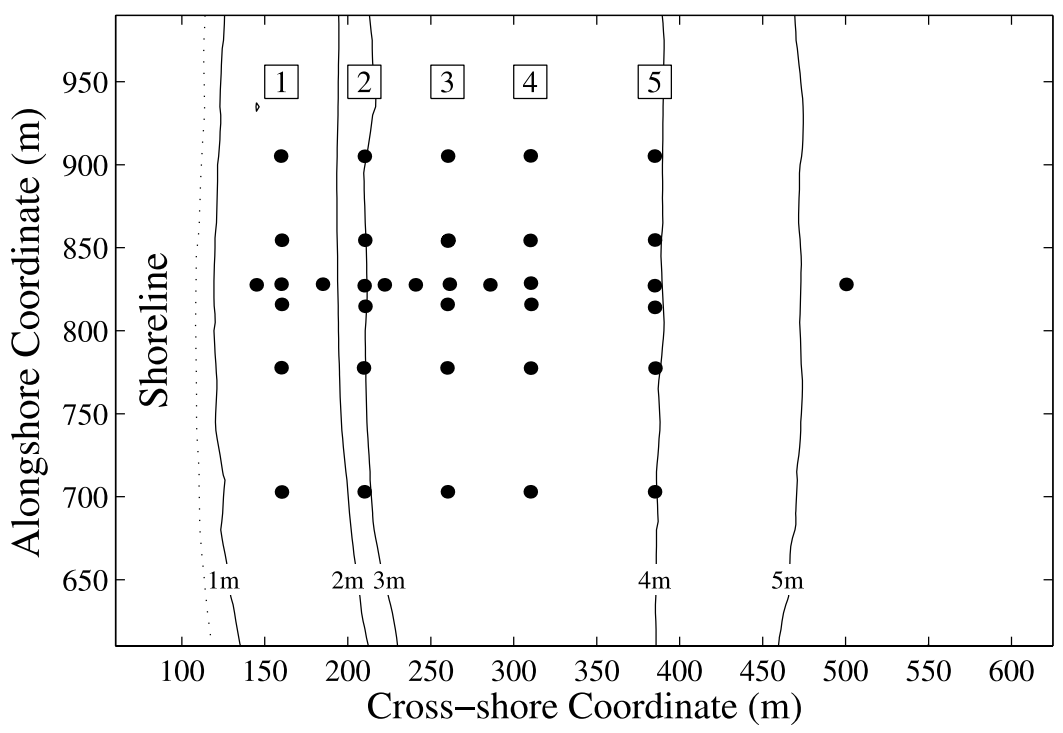

Figure 1. Plan view of the sensor arrays. Each solid circle denotes a colocated pressure sensor, bidirectional electromagnetic current meter, and sonar altimeter (that measures the distance from a known vertical elevation to the evolving seafloor). Each numbered box shows the cross-shore location of a 200-mlong, six-element, alongshore-oriented array. The alongshore separations between adjacent current meters, from north to south (top to bottom), are approximately 50, 27, 12, 38, and $75 \mathrm{~m}$. Contours show the depth below mean sea level on 2 October 1997, smoothed with a 20-m running mean. The coordinate system of the Field Research Facility is used, and the shoreline (dotted line) is located at cross-shore coordinate $x \approx 100 \mathrm{~m}$.

shear waves [Özkan-Haller and Kirby, 1999]. Dodd et al. [2000] survey the shear wave literature.

[6] Here, previous studies of shear waves at a single cross-shore location (using one alongshore array) are extended by examining the cross-shore variation of shear wave properties with 5 alongshore arrays. The field experiment, data processing, and case examples are described in section 2. In section 3, shear wave characteristics observed over 4 months are related empirically to the mean alongshore current. In section 4, shear waves in the case examples are compared with linear stability theory. The results are summarized in section 5 .

\section{Experiment and Data Analysis}

[7] Observations were collected on a sandy beach near Duck, North Carolina, during the summer and fall of 1997, as part of the SandyDuck experiment. Colocated pressure gauges and bidirectional current meters (PUV) were deployed at 11 locations along a cross-shore transect extending between about 1.0 and $5.5 \mathrm{~m}$ water depth, approximately 50 to $300 \mathrm{~m}$ from the shoreline. At 5 cross-shore locations, PUV were deployed at 6 alongshore locations spanning $200 \mathrm{~m}$ (Figure 1). Incident swell and sea wave data were available from a permanent array of pressure sensors located in $8-\mathrm{m}$ water depth about $800 \mathrm{~m}$ from shore [Long and Oltman-Shay, 1991]. Data gaps were infrequent, except at the shallowest alongshore array (array 1, Figure 1) where current meters often were above the sea surface at low tide, sometimes were buried by sand accretion, and occasionally failed mechanically owing to hammering by plunging waves.
[8] Bathymetric surveys were conducted with an amphibious vehicle several times per week and supplemented with continuous estimates of bed level obtained from altimeters colocated with the PUV. Although shadowing by a crossshore-oriented pier located about $200 \mathrm{~m}$ south of the instrumented region reduced the heights of waves arriving obliquely from the south by as much as $15 \%$ at the southern end of the arrays [Elgar et al., 2001], the observed bathymetry (Figure 1) and mean (1-hour-averaged) circulation usually was alongshore homogeneous (within the measurement accuracy) [Herbers et al., 2003].

[9] Pressure and velocity data were collected at $2 \mathrm{~Hz}$ and processed in 3-hour segments that were quadratically detrended and divided into 448-s-long, demeaned, Hanning-windowed ensembles with $50 \%$ overlap. At each alongshore array, cross spectra (normalized to remove sensor calibration errors [Munk et al., 1964]) with about 24 degrees of freedom and $0.0011-\mathrm{Hz}$ frequency resolution were used to estimate alongshore wave number-frequency spectra $E(k, f)$ separately for pressure $p\left(E^{p}(k, f)\right)$ and for cross-shore $u$ and alongshore $v$ velocity components $\left(E^{u}(k, f)\right.$ and $\left.E^{v}(k, f)\right)$ using the iterative maximum likelihood estimator (IMLE) [Pawka, 1983]. Shear waves appear in $E^{u, v}(k, f)$ as an approximately linear ridge of elevated energy corresponding to nondispersive propagation in the same direction as $V$ [e.g., Oltman-Shay et al., 1989; Howd et $a l ., 1991]$. Example $E^{u}(k, f)$, for shear wave $k$ with sign corresponding to propagation in the direction of $V$, are shown in Figures 2 (left) and 3 (left). The shear wave ridge sometimes extended to the Nyquist wave number $\left(\approx 0.04 \mathrm{~m}^{-1}\right)$, but energy levels at these high wave numbers were relatively low [Noyes, 2002]. 
[10] At each frequency, energy associated with $k$ outside the theoretical range for surface gravity waves is attributed to shear waves, and thus the frequency spectrum of shear waves $E_{s w}(f)$ is

$$
E_{s w}(f)=E(f)-E_{g w}(f),
$$

where $E(f)$ is the combined (gravity plus shear waves) frequency spectrum and $E_{g w}(f)$ is the frequency spectrum of gravity waves, defined as

$$
E(f)=\int_{-0.04 \mathrm{~m}^{-1}}^{0.04 \mathrm{~m}^{-1}} E(k, f) d k
$$
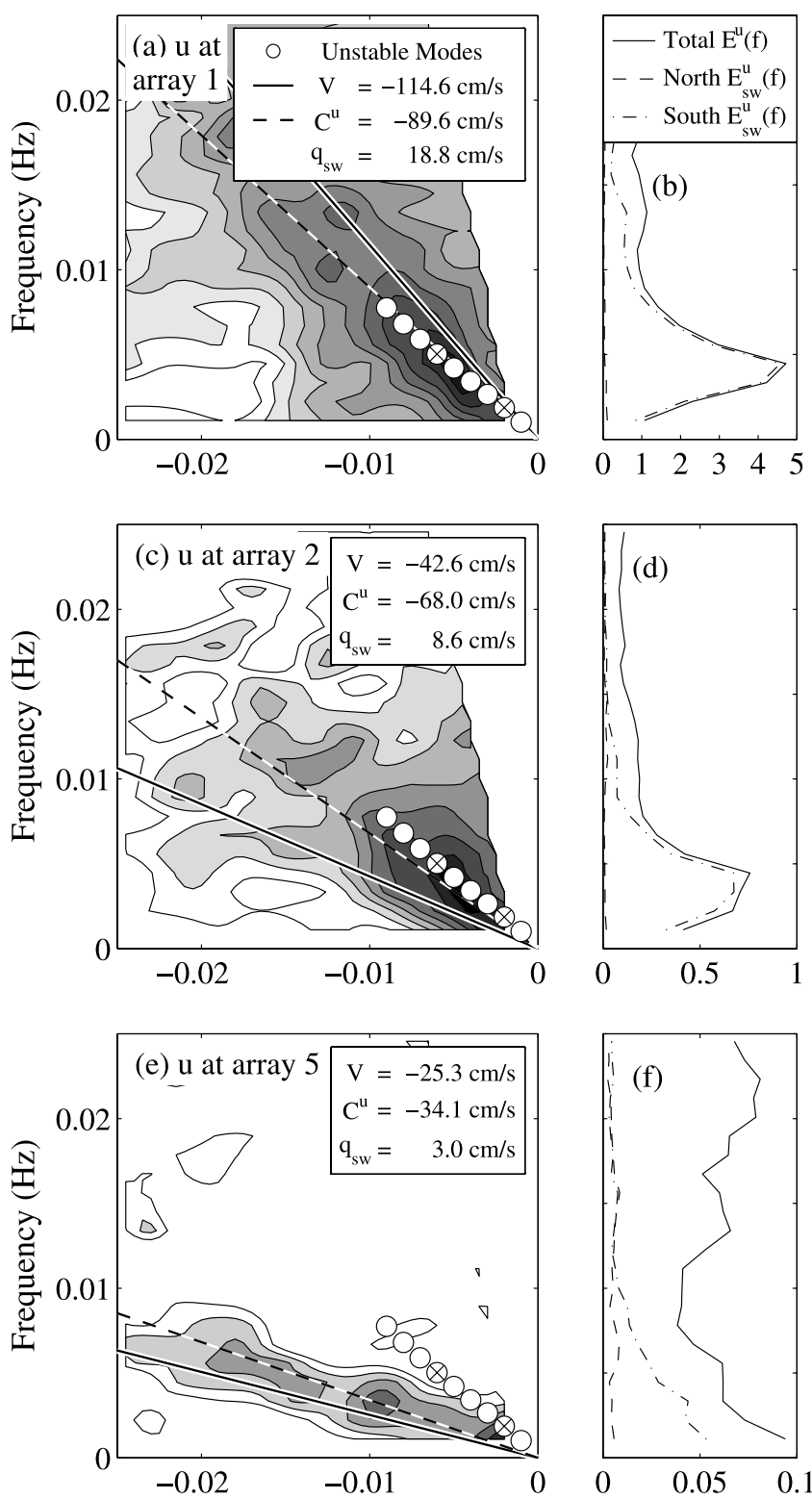

Cyclic Alongshore Wavenumber $\left(\mathrm{m}^{-1}\right) \quad \times 10^{4} \mathrm{~cm}^{2} / \mathrm{s}$

$$
E_{g w}(f)=\int_{k_{0-}(f)-\delta}^{k_{0+}(f)+\delta} E(k, f) d k
$$

Gravity and shear waves are delineated in $(k, f)$ space by $k_{0 \pm}(f)$, the wave numbers of upcoast and downcoast propagating mode 0 edge waves, plus a small wave number offset $\delta$ (here $0.0015 \mathrm{~m}^{-1}$ ) that reduces spectral leakage from gravity waves into shear waves [Howd et al., 1991]. The linear shallow water equations were solved numerically for $k_{0 \pm}(f)$ with the observed bathymetry and $V(x)$ [Howd et $a l ., 1992]$. The frequency spectra $E(f), E_{g w}(f)$, and $E_{s w}(f)$ were computed separately for $u, v$, and $p$ (as indicated by a superscript). The shear wave velocity spectra $E_{s w}^{u}(f)$ and $E_{s w}^{v}(f)$ were further divided into northward and southward (upcoast and downcoast) propagating components (broken curves in Figures 2 (right) and 3 (right)).

[11] The total infragravity horizontal velocity variance $q^{2}$, and the contributions of gravity waves $q_{\mathrm{g} w}^{2}$ and shear waves $q_{\mathrm{s} w}^{2}$, are given by

$$
\begin{gathered}
q^{2}=\int_{0.00165 \mathrm{~Hz}}^{0.025 \mathrm{~Hz}}\left(E^{u}(f)+E^{v}(f)\right) d f, \\
q_{\mathrm{g} w}^{2}=\int_{0.00165 \mathrm{~Hz}}^{0.025 \mathrm{~Hz}}\left(E_{g w}^{u}(f)+E_{g w}^{v}(f)\right) d f, \\
q_{\mathrm{s} w}^{2}=\int_{0.00165 \mathrm{~Hz}}^{0.025 \mathrm{~Hz}}\left(E_{s w}^{u}(f)+E_{s w}^{v}(f)\right) d f .
\end{gathered}
$$

Shear wave energy $E_{s w}(f)$ usually was low for $f>0.025 \mathrm{~Hz}$. Statistical fluctuations in the cross spectra along with the relatively long shear wave wavelengths at low frequencies blur the estimated $E(k, f)$. Frequencies below $0.00165 \mathrm{~Hz}$ $(\approx 10$-min period) are excluded because their long (nominally 300-600 m) wavelengths were not resolved sufficiently to be distinguished from gravity waves.

Figure 2. IMLE-estimated alongshore wave numberfrequency spectra of shear wave cross-shore velocity $E^{u}(k, f)$ for 0400-0700 EST, 2 October 1997, at alongshore arrays (a) 1, (c) 2, and (e) 5 (Figure 1). Results are shown only for southward propagating shear waves (e.g., $k<0$ and $|k|$ greater than the theoretical maximum for gravity waves). The grey scale for all arrays is at the figure bottom. (b), (d), and (f) For each array, frequency spectra of northward (dashed curve) and southward (dotted curve) propagating shear waves (obtained by integrating $E^{u}(k, f)$ at each $f$ over the appropriate $k$ ) and the total (shear plus gravity waves, solid curve) frequency spectrum $E^{u}(f)$. The scales differ by as much as a factor of 50. In Figures 2a, 2c, and 2e the shear wave phase speed $C^{u}$ (given in the legends) equals the slope of the best fit line (dashed) to the observed ridge. The solid line corresponds to a nondispersive propagation speed equal to $V$ observed at that array. The circles are the $(k, f)$ of linearly unstable modes (phase speed $\approx 83 \mathrm{~cm} \mathrm{~s}^{-1}$ ), as described in section 4.1. The cross-shore variation of $E(k, f)$ at selected $(k, f)$ indicated with crossed circles are shown in Figures $13 \mathrm{a}$ and $13 \mathrm{~b}$. 

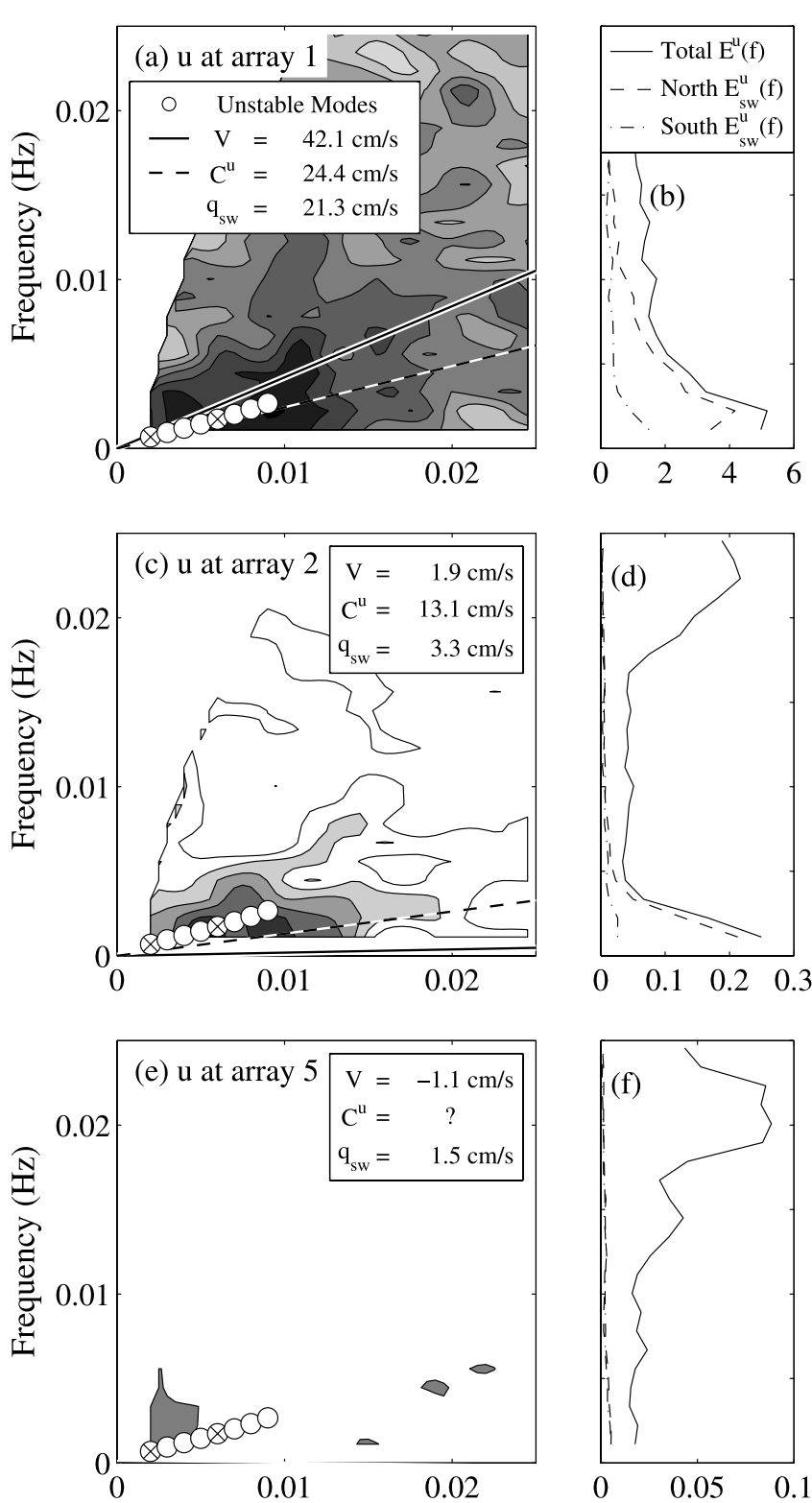

Cyclic Alongshore Wavenumber $\left(\mathrm{m}^{-1}\right) \quad \times 10^{4} \mathrm{~cm}^{2} / \mathrm{s}$

\begin{tabular}{|c|c|c|c|c|c|}
\hline & & & & & \\
\hline $10^{6}$ & $10^{7}$ & $\mathrm{~cm}^{3} / \mathrm{s}$ & $10^{8}$ & $10^{9}$ \\
& & & &
\end{tabular}

Figure 3. Alongshore wave number-frequency spectra of shear wave cross-shore velocity $E^{u}(k, f)$ for $0100-0400$ EST, 28 August 1997, at alongshore arrays (a) 1, (c) 2, and (e) 5 (the shear wave energy at array 5 is too low to estimate the phase speed $C^{u}$ accurately). The cross-shore variation of $E(k, f)$ at the $(k, f)$ of selected linearly unstable modes (phase speed $\approx 30 \mathrm{~cm} \mathrm{~s}^{-1}$, indicated with crossed circles) are shown in Figures 13c and 13d. (b), (d), and (f) For each array, frequency spectra of total (solid curve), northward (dashed curve), and southward (dotted curve) propagating shear waves. The format is similar to Figure 2, except that here, shear waves are propagating northward.
[12] The nondispersive shear wave phase speed $C$ is estimated as the slope of the best fit line to the shear wave ridge in each $E^{u}(k, f)$ and $E^{v}(k, f)$. At each $k$ in the shear wave domain (e.g., $|k|$ greater than is allowed for gravity waves and less than $\left.0.04 \mathrm{~m}^{-1}\right), f_{p}(k)$ is defined as the frequency of the maximum $E(k, f)$ A least squares fit to the coordinates $\left(k, f_{p}(k)\right)$, weighted by the magnitude of the peaks $E\left(k, f_{p}(k)\right)$ and constrained to pass through the $(k, f)$ coordinate origin, yields a line with slope $C\left(C^{u}\right.$, the phase speed based on $E^{u}(k, f)$, is shown in Figures 2, 3, and $4 d$ ). The lowest-frequency bands often are the most energetic, so $C$ is determined by the dominant wave numbers in these bands, and can be sensitive to the lower-frequency bound (here $0.00165 \mathrm{~Hz}$ ). Other ridge-fitting methods yield statistically similar $C$.

[13] The small sandbar in approximately 4-m depth (Figure $4 \mathrm{a}$ ) caused breaking in only a few cases. The largest $V(x)$ and shear wave rms velocity fluctuations $q_{\text {sw }}(6)$ usually were observed close to shore (Figures $4 b$ and $4 c$ ). Estimates of $q_{\mathrm{sw}}$ using the " $R$ " method [Lippmann et al., 1999] and colocated pressure and velocity sensors are maximum at array 1 in these examples. Although the $V$ and $q_{\text {sw }}$ maxima were usually resolved by the cross-shore array, the region onshore of the maxima is not well resolved with these observations (section 3).

[14] On 2 October, $|V|>25 \mathrm{~cm} \mathrm{~s}^{-1}$ at all 5 arrays (Figure 4b), and at the most energetic frequencies the total (shear plus gravity wave) cross-shore velocity spectrum $E^{u}(f)$ is dominated by southward propagating shear waves $(f<0.005 \mathrm{~Hz}$ in Figures $2 b, 2 d$, and $2 \mathrm{f}$ ). Shear wave phase speeds varied with cross-shore location $\left(C^{u}=-89\right.$ and $-34 \mathrm{~cm} \mathrm{~s}^{-1}$ at arrays 1 and 5, respectively, Figures $2 \mathrm{a}$ and 2e). On 28 August, $|V|>25 \mathrm{~cm} \mathrm{~s}^{-1}$ only at array 1, where a ridge is discernible. Ridges become less distinct with increasing offshore distance and were absent at array 5 (Figure 3e).

[15] Propagating spatial patterns in the flow field were isolated with complex empirical orthogonal function (CEOF) analysis that utilizes cross spectra between all sensor pairs and both velocity components (Appendix A). On 2 October, the dominant spatial mode explains more than half the frequency band variance at two representative shear wave frequencies (Figure 5). The dominant patterns have maximum amplitude near the shoreline (note the log scale of the flow vectors in Figure 5), where shear wave energy is highest. The CEOF alongshore propagation speed near the shoreline $\left(\approx 60-80 \mathrm{~cm} \mathrm{~s}^{-1}\right)$ is similar to the nondispersive phase speeds based on IMLE wave numberfrequency spectra at the shallow arrays $\left(C^{u}\right.$ in Figures $2 \mathrm{a}$ and $2 \mathrm{c})$.

\section{Statistical Analysis of Shear Wave Characteristics}

[16] A 3-hour data record at a particular alongshore array was included in the statistical analysis if the array resolution was not degraded substantially by nonfunctional instruments, and if the $E(k, f)$ met conditions associated with a well-defined shear wave ridge (Appendix B). The retained runs include a wide range of incident wave conditions. Significant wave heights in 8-m water depth reached $338 \mathrm{~cm}$. Energetic incident waves usually were obliquely 


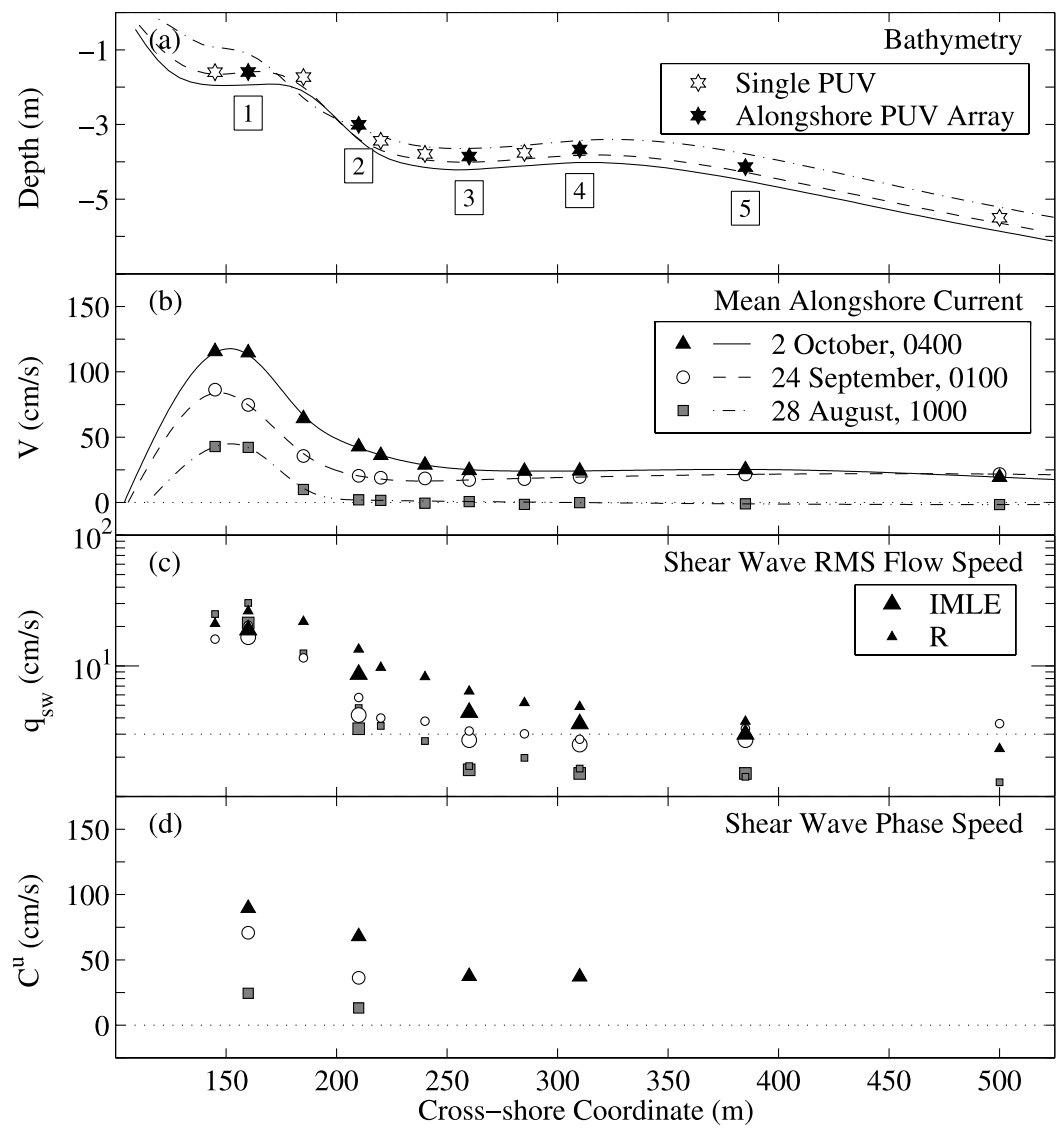

Figure 4. (a) Mean depth, (b) observed mean alongshore current $V$ (symbols) (curves are cubic spline fits constrained to vanish at the shoreline), (c) shear wave RMS flow speed $q_{\mathrm{sw}}(6)$, and (d) shear wave phase speed $C^{u}$ (based on cross-shore velocity fluctuations) versus the cross-shore coordinate for three 3-hour periods (dates and start times (EST) are in the Figure 4b legend). The mean alongshore current was directed southward on 2 October and 24 September, and the signs of $V$ and $C^{u}$ are inverted to facilitate comparison with the northward flow on 28 August. Each open star in Figure 4a represents a colocated pressure and bidirectional current meter where $q_{\mathrm{sw}}$ is based on the " $R$ " method [Lippmann et al., 1999]. The cross-shore positions of five alongshore arrays are indicated with solid stars and labeled with boxed numbers. At the array locations, array-averaged values are shown for $V$ - and $R$-estimated $q_{\mathrm{sw}}$, and IMLE wave number-frequency spectra are used to estimate $q_{\mathrm{sw}}$ (IMLE) and $C^{u}$. Over the entire data set, $R$ and IMLE estimates of $q_{\mathrm{sw}}$ are highly correlated, with the $R$ estimates biased high by about $20 \%$ [Noyes et al., 2002]. When $q_{\mathrm{sw}}<3 \mathrm{~cm} \mathrm{~s}^{-1}$ (indicated by the horizontal dotted line in Figure 4c), estimates of shear wave properties may be inaccurate, and $C^{u}$ is not shown in Figure $4 \mathrm{~d}$.

incident to the beach so that offshore root mean square wave height $H_{\text {rms }}$, offshore radiation stress $S_{y x}$, surf zone $V$, and $q_{\mathrm{sw}}$ were mutually correlated (Figure 6).

\subsection{Pressure Fluctuations}

[17] The alongshore wave number-frequency spectra of pressure fluctuations $E^{p}(k, f)$ always were dominated by gravity waves at infragravity frequencies. However, when shear waves were energetic (e.g., $\left.q_{\mathrm{sw}}>3 \mathrm{~cm} \mathrm{~s}^{-1}\right), E^{p}(k, f)$ often had detectable energy concentrations in the same region of $k-f$ space as occupied by shear wave ridges in velocity $E^{u, v}(k, f)$. When $q_{\mathrm{sw}}$ was small, $E^{p}(k, f)$ were featureless in the shear wave $k-f$ domain, and may be dominated by spectral leakage from more energetic gravity waves [Noyes, 2002].

[18] The rigid lid assumption, often used to model shear waves, was tested by integrating $E^{p}(k, f)$ over the same $k$ - $f$ regions as $E^{u, v}(k, f)$ (equations (1)-(6)) to obtain the corresponding gravity and shear wave pressure variances $\left(p_{\mathrm{gw}}^{2}\right.$ and $p_{\mathrm{sw}}^{2}$, respectively). Theoretically, shear waves have no pressure fluctuations (to lowest order), so $g p_{\mathrm{sw}}^{2} / h q_{\mathrm{sw}}^{2}=0$ (where $g$ is gravitational acceleration), whereas potential and kinetic energy are equipartitioned in gravity waves so that (with some additional assumptions) $g p_{\mathrm{gw}}^{2} / h q_{\mathrm{gw}}^{2}=1$ [Lippmann et al., 1999]. The observed $g p_{\mathrm{sw}}^{2} / h q_{\mathrm{sw}}^{2}$ usually is less than 0.1 , supporting the rigid lid assumption. The observed $g p_{\mathrm{gw}}^{2} / h q_{\mathrm{gw}}^{2}$ (mean of 0.79 and standard deviation of 0.28 ) suggests that gravity wave energy does not deviate strongly from equipartition in the $0.00165-0.025-\mathrm{Hz}$ frequency band.

\subsection{Polarization and Magnitude of Shear Wave Velocity Fluctuations}

[19] At all cross-shore locations and for all conditions, the observed shear wave velocity fluctuations are weakly polarized in the cross-shore direction $\left(u_{\mathrm{sw}} / v_{\mathrm{sw}} \approx 1.2\right.$, Figure 7). 
2 October

CEOF \#1 of $0.0017-0.0028 \mathrm{~Hz}(59 \%$ of the variance)
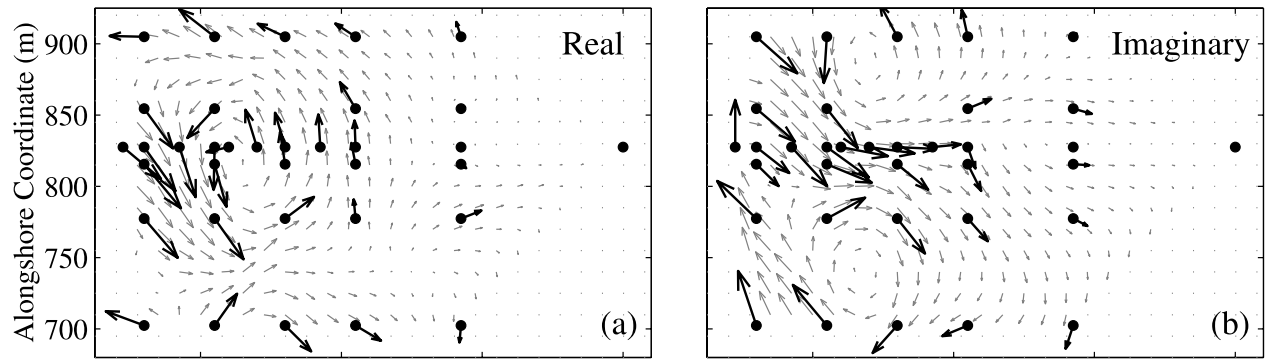

CEOF \#1 of $0.0039-0.0050 \mathrm{~Hz}(62 \%$ of the variance)
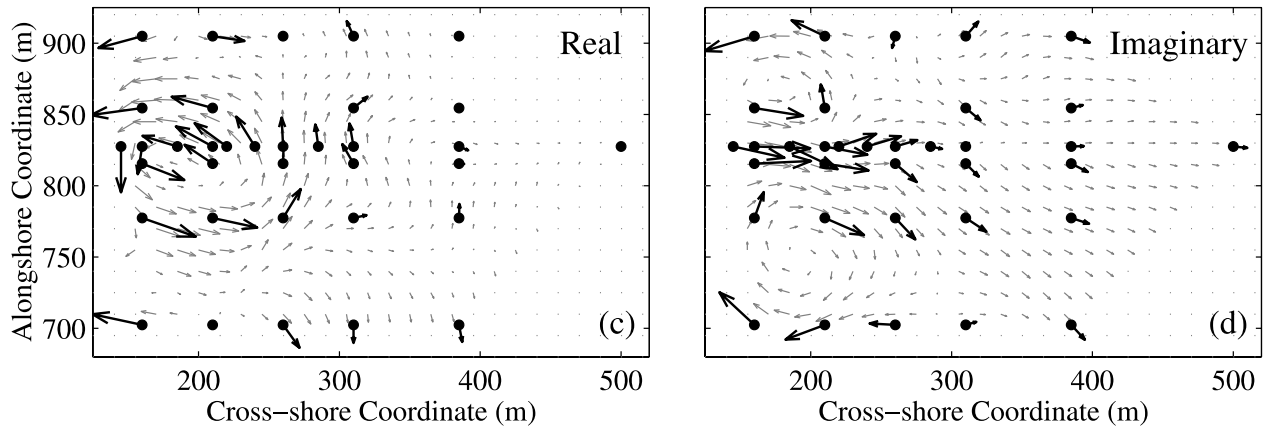

Figure 5. Dominant velocity CEOF spatial patterns of the frequency bands (a) and (b) $0.0017-0.0028 \mathrm{~Hz}$ and (c) and (d) $0.0039-0.0050 \mathrm{~Hz}$ for 2 October. Large black dots indicate the locations of operational current meters. The direction of the solid black arrows indicates the direction of the local CEOF flow, and the arrow length depends logarithmically on the CEOF flow magnitude (the length is set equal to zero if the local speed is less than $1 / 100$ of the maximum speed). The smaller shaded arrows, linear interpolations between the solid black arrows, have reduced magnitudes for clarity and are intended to aid visualization of the spatial patterns. Combination of the (left) real and (right) imaginary parts of the flow field at different phases of a shear wave cycle shows circulation cells propagating alongshore at about $60-80 \mathrm{~cm} \mathrm{~s}^{-1}$.

Gravity waves are more strongly cross-shore polarized, and $u_{\mathrm{gw}} / v_{\mathrm{gw}}$ increases from about 1.5 to 2.0 with increasing $q_{\mathrm{gw}}$. The orbital motion in a broad spectrum of edge waves is nearly isotropic $\left(u_{\mathrm{gw}} / v_{\mathrm{gw}} \approx 1\right)$ in contrast to the cross-shorepolarized flow field $\left(u_{\mathrm{gw}} / v_{\mathrm{gw}}>1\right)$ of shore normal propagating leaky waves. The observed increase of $u_{\mathrm{gw}} / v_{\mathrm{gw}}$ with increasing $q$ is consistent with the suggestion that edge wave trapping is less efficient when incident sea swell are energetic $\left(V, q_{\mathrm{sw}}\right.$, and $q_{\mathrm{gw}}$ are also elevated) and dissipation is stronger [Herbers et al., 1995].

[20] Shear wave energy observed at array 1, the array nearest the shoreline, was correlated with both the observed $|V|$ (correlation $r=0.75$; Figure 8 ) and the modeled $\left|V_{x}\right|(r=0.64$, Appendix C), similar to Howd et al. [1991]. Correlations with $q_{\mathrm{sw}}$ are similar using the observed, rather than the modeled, maximum $\left|V_{x}\right|$. Farther from shore, $q_{\mathrm{sw}}$ is not correlated with $\left|V_{x}\right|$, but is correlated with the local $|V|$ ( $r$ between 0.60 and 0.76 ). At all 5 arrays, $q_{\text {sw }}$ is about $10-40 \%$ of the local $|V|$ (Figure 8), similar to the percentage observed by Howd et al. [1991] near the shoreline.

\subsection{Relative Magnitude of Gravity and Shear Wave Velocity Fluctuations}

[21] At all cross-shore locations, the fraction of the infragravity variance (here $0.00165-0.025 \mathrm{~Hz}$ ) attributed to shear waves $\left(q_{\mathrm{sw}}^{2} / q^{2}\right.$, the remainder of the variance is in gravity waves) increased with increasing $V$ (correlation between $0.30-0.59)$. When $V \approx 100 \mathrm{~cm} \mathrm{~s}^{-1}, q_{\mathrm{sw}} \approx$ $20 \mathrm{~cm} \mathrm{~s}^{-1}$, and $q_{\mathrm{sw}}^{2} / q^{2} \approx 0.6$. Gravity waves were polarized more strongly in the cross-shore direction than the approximately isotropic shear waves (Figure 7), so the fractional contribution of shear waves to the total (shear plus gravity wave) $v$ variance is larger than their fractional contribution to the total $u$ variance. When $V \approx 100 \mathrm{~cm} \mathrm{~s}^{-1}$, shear waves contributed about $70 \%$ and $50 \%$ of the infragravity $v$ and $u$ variances, respectively.

\subsection{Shear Wave Phase Speeds}

[22] Observed shear wave phase speeds $C^{u}$ and alongshore currents $V$ are highly correlated $(r>0.90)$ and approximately equal in magnitude (Figures $4 b, 4 d$, and 9). Phase speed estimates based on cross-shore velocity $C^{u}$ are about $10 \%$ larger than estimates based on alongshore velocity $C^{v}$ [Noyes, 2002]. As discussed below, the phase speeds observed near the shoreline (where $V$ is largest and shear waves are most energetic) also are approximately equal to the phase speeds of linearly unstable modes.

\subsection{Shear Wave-Mean Flow Kinetic Energy Balance}

[23] The observed total kinetic energies of the mean alongshore current $\left(\mathrm{KE}_{\mathrm{mac}}\right)$ and of shear waves $\left(\mathrm{KE}_{\mathrm{sw}}\right)$ 


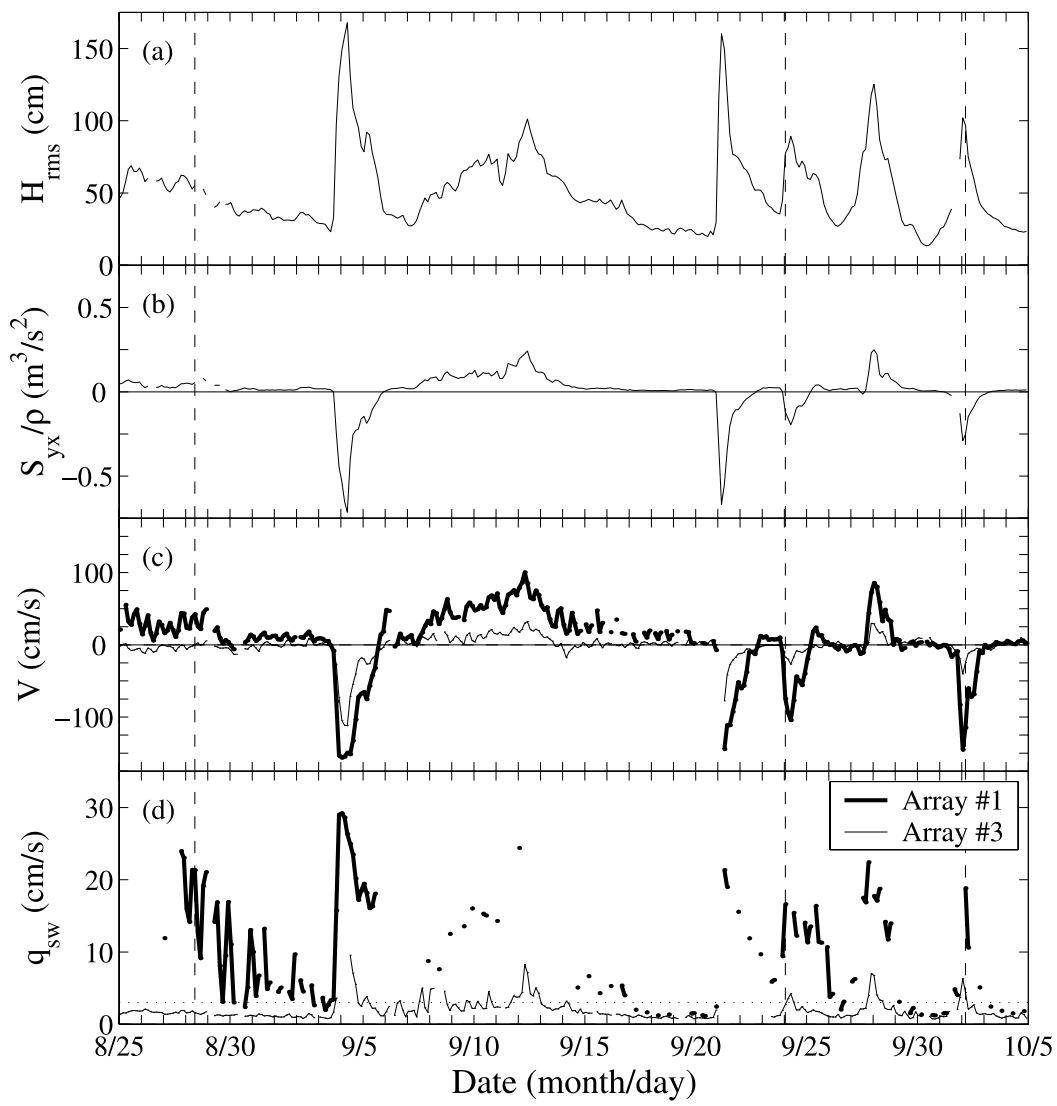

Figure 6. (a) Root mean square incident wave height $H_{\mathrm{rms}}$ and (b) normalized radiation stress $S_{y x} / \rho$ of the frequency band $0.044-0.308 \mathrm{~Hz}$ at the array in 8-m-deep water, and (c) mean alongshore current $V$ and (d) shear wave rms flow speed $q_{\mathrm{sw}}$ at arrays 1 and 3 versus time for 1.5 months, representative of the 4-month-long experiment. For a northward flowing current, $V>0$, and for waves from the south, $S_{y x}>0$. Array 3 is $200 \mathrm{~m}$ offshore of array 1 (Figure 1). The vertical dashed lines indicate case examples shown in Figure 4. The horizontal dotted line in Figure $6 \mathrm{~d}$ is the threshold $\left(q_{\mathrm{sw}}=3 \mathrm{~cm} \mathrm{~s}^{-1}\right)$ below which array estimates of shear wave properties may be inaccurate.

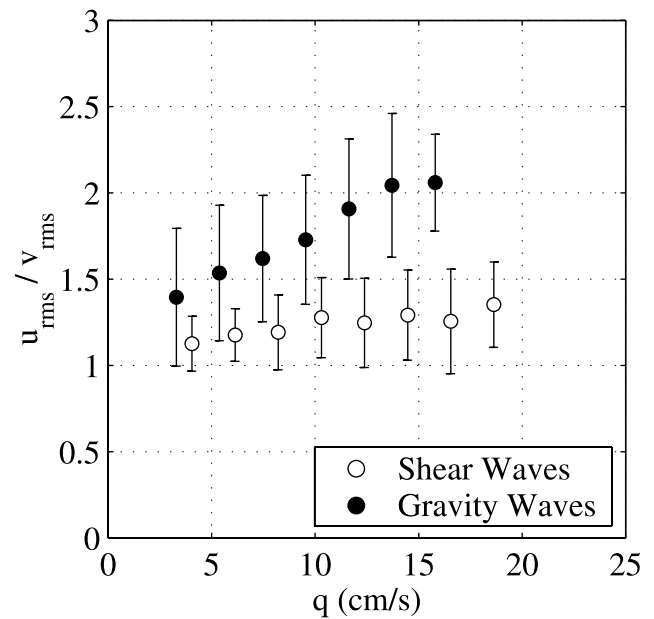

Figure 7. The ratio of RMS cross-shore $\left(u_{\mathrm{rms}}\right)$ to alongshore $\left(v_{\text {rms }}\right)$ flow speeds versus total RMS flow speed $q$ for shear (open circles) and gravity (solid circles) waves. The means (circles) and standard deviations (vertical bars) are based on $2-\mathrm{cm} \mathrm{s}^{-1}$-wide bins.

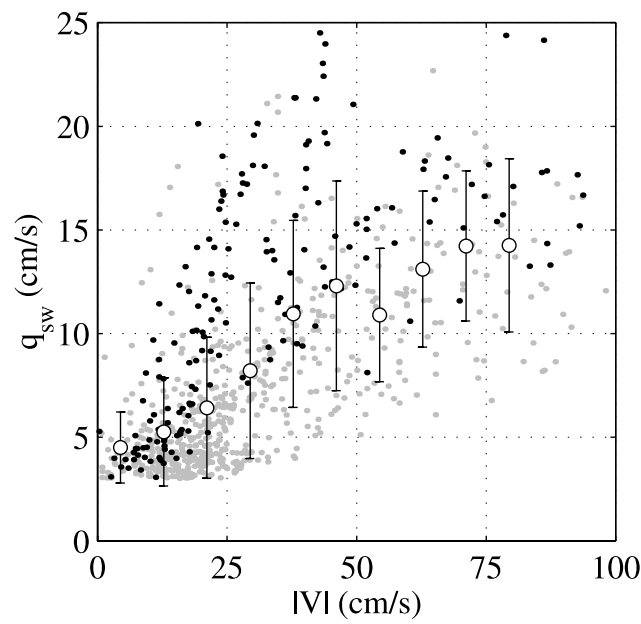

Figure 8. Shear wave RMS flow speed $q_{\mathrm{sw}}$ versus the magnitude of the local mean alongshore current $|V|$. There are 788 estimates (black dots are array 1 and shaded dots are arrays 2-5), and the means (circles) and standard deviations (vertical bars) are based on $8-\mathrm{cm} \mathrm{s}^{-1}$-wide bins using all arrays. The $q_{\mathrm{sw}}$ observed at array 1 tend to be larger than $q_{\mathrm{sw}}$ at the other arrays for the same $|V|$. 


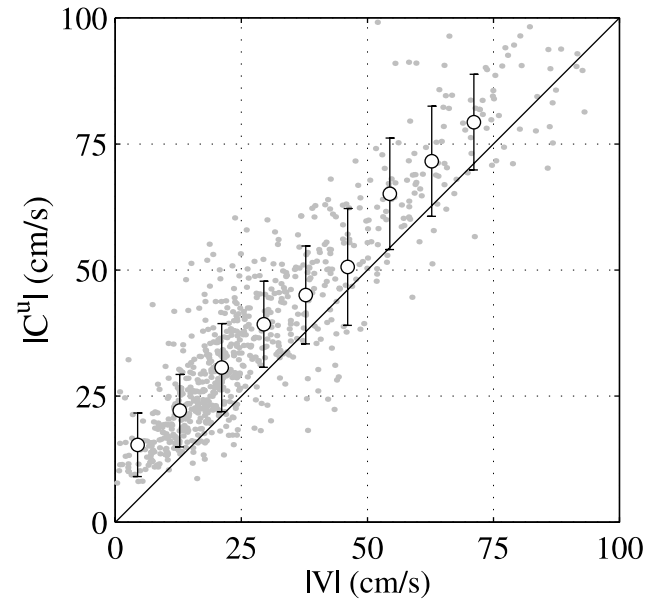

Figure 9. Observed shear wave phase speed $\left|C^{u}\right|$ versus the magnitude of the local mean alongshore current $|V|$. Data from all arrays are included. There are 788 estimates (shaded dots), and the means (circles) and standard deviations (vertical bars) are based on $8-\mathrm{cm} \mathrm{s}^{-1}$-wide bins. The solid line is $\left|C^{u}\right|=|V|$.

were estimated by integrating from the shoreline over the cross-shore extent of the array,

$$
\begin{aligned}
\mathrm{KE}_{\mathrm{mac}} & =\int \frac{1}{2} \rho h V^{2} d x, \\
\mathrm{KE}_{\mathrm{sw}} & =\int \frac{1}{2} \rho h q_{\mathrm{s} w}^{2} d x .
\end{aligned}
$$

As $K E_{\text {mac }}$ increases, $K E_{\mathrm{sw}}$ increases, but the ratio $K E_{\mathrm{sw}} /$ $K E_{\text {mac }}$ decreases from roughly 0.2 to 0.01 (Figure 10 ).

[24] The depth- and short-time-averaged (over a few incident wave periods) nonlinear shallow water equations with the rigid lid assumption, alongshore homogeneous bathymetry $h(x)$, and steady forcing by wind and wave breaking, yield a balance for the local shear wave kinetic energy $\left(\mathrm{ke}=\frac{1}{2} \rho h\left(u^{2}+v^{2}\right)\right)$

$$
\frac{1}{\rho} \partial_{t}\langle\mathrm{ke}\rangle=-h\langle u v\rangle V_{x}-2 \frac{\mu}{\rho h}\langle\mathrm{ke}\rangle+\text { other terms }
$$

where the flow has been decomposed into the sum of longtime-averaged (many shear wave periods, $\langle\cdot\rangle$ ) alongshore homogeneous mean currents $(0, V(x))$ and shear wave fluctuations $(u, v)$. Bottom stress has been parameterized with a simple linear drag law $(\tau=(\mu / h)(u, v))$ with a spatially constant bottom drag parameter $\mu$. Shear instabilities extract energy from the mean flow where $-h\langle u v\rangle V_{x}>0$, and transfer energy to the mean flow where $-h\langle u v\rangle V_{x}<0$. Bottom drag $(-2 \mu\langle\mathrm{ke}\rangle / \rho h)$ removes energy from shear instabilities. The remaining terms, representing advection of shear wave energy by mean flows, turbulent mixing and diffusion of shear wave energy, and work done by pressure gradients [Dodd and Thornton, 1990], could not be estimated accurately with the present observations.

[25] The shear wave contribution $\langle u v\rangle$ to $-h\langle u v\rangle V_{x}$ was estimated by integrating the cospectrum of colocated $u$ and $v$ over the infragravity frequency band. The contribution of gravity waves to $\langle u v\rangle$ was neglected. Although gravity waves contribute significantly to the infragravity velocity variance, these waves are predominantly standing in the cross shore with $u$ and $v$ fluctuations that tend to be in quadrature, and thus the associated radiation stress $\langle u v\rangle$ is expected to be small. To reduce the considerable noise in $\langle u v\rangle$, only alongshore-averaged $\langle u v\rangle$ estimates (i.e., from the alongshore arrays) were considered. The bottom drag parameter $\mu$ in the linear drag law was estimated following Dodd et al. [1992] as

$$
\mu=\frac{2}{\pi} u_{0} c_{f}
$$

where the bottom drag coefficient $c_{f}=0.003$, and a representative wave orbital velocity within the surf zone $u_{0}=\sqrt{\pi g \gamma H_{\mathrm{rms}} / 16}$, where $\gamma=H_{\mathrm{rms}} / h=0.32$. Although $H_{\text {rms }}$ is variable within the surf zone, for simplicity a constant surf zone-averaged value, approximated as one half of $H_{\text {rms }}$ measured in 8-m water depth, was used.

[26] Although scattered, the trend of the cross-shore variation of the ratio of shear wave energy production $P$ to shear wave energy dissipation by bottom drag $D$,

$$
\frac{P}{D}=-\frac{h\langle u v\rangle V_{x}}{\frac{2 \mu}{\rho h}\langle\mathrm{ke}\rangle},
$$

is similar to the $P / D$ patterns of two numerical simulations of finite amplitude shear waves (Figure 11). On average,

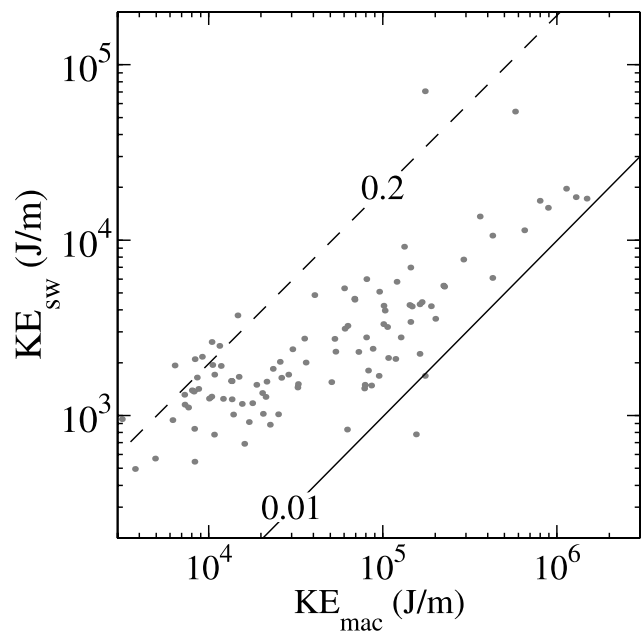

Figure 10. Cross-shore-integrated shear wave kinetic energy $\mathrm{KE}_{\mathrm{sw}}$ (equation (8)) versus cross-shore-integrated kinetic energy of the mean alongshore current $\mathrm{KE}_{\text {mac }}$ (equation (7)). There are 105 estimates (shaded dots). The solid and dashed lines correspond to $\mathrm{KE}_{\mathrm{sw}}=0.01 \mathrm{KE}_{\text {mac }}$ and $\mathrm{KE}_{\mathrm{sw}}=0.2 \mathrm{KE}_{\mathrm{mac}}$, respectively. The linear correlation coefficient $(r=0.79)$ was computed from the $\log _{10}$ of the kinetic energies. In the cases shown, $V_{\max }>30 \mathrm{~cm} \mathrm{~s}^{-1}$, and array 1 (where shear wave energy often is maximum) was operational. The $R$ estimates of shear wave velocity variance $q_{\mathrm{s} w}^{2}$ were used rather than IMLE estimates because $R$ estimates can be made at 11 cross-shore locations. To reduce bias [Noyes et al., 2002], $R$ estimates of shear wave variance $q_{\mathrm{s} w}^{2}$ were divided by the bias $\left(q_{\mathrm{sw}, \mathrm{R}}^{2} / q_{\mathrm{sw}, \mathrm{IMLE}}^{2}\right.$, on average about 1.2) observed at array 1. The estimates were discarded if $q_{\mathrm{sw}, \mathrm{IMLE}}<3 \mathrm{~cm} \mathrm{~s}^{-1}$ at the closest alongshore array. 


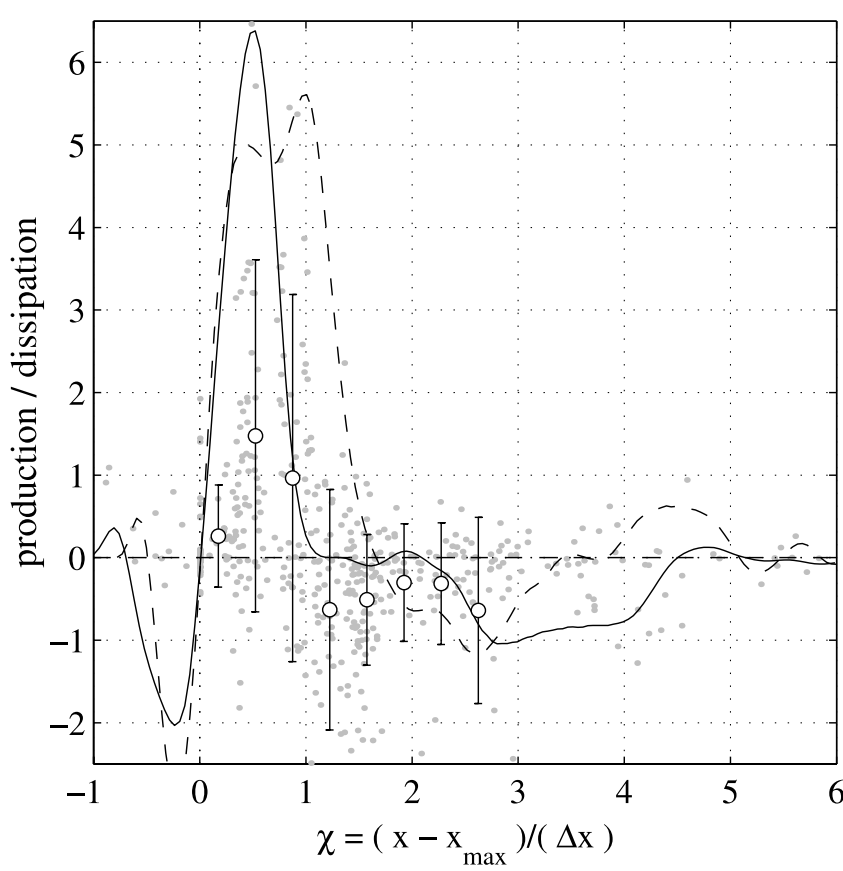

Figure 11. The ratio of the rate of shear wave energy production to shear wave energy dissipation by bottom drag $(P / D$; equation $(11))$ versus $\chi=\left(x-x_{\max }\right) / \Delta x$, the crossshore distance from the location $x_{\max }$ of the maximum mean alongshore current $V_{\max }$ normalized by the width $\Delta x$ of the region of strong $V$ (estimated as the distance from $x_{\max }$ to the location where $V$ is midway between $V_{\max }$ and the crossshore average of $V$ ). Each of the 505 estimates (shaded dots) is based on alongshore array-averaged $P$ and $D$. The means (circles) and standard deviations (vertical bars) are based on $0.3 \chi$-wide bins. The solid and dashed curves are results from numerical simulations of finite amplitude shear waves [after Allen et al., 1996] for two different $V(x)$ with parameters selected such that nonlinearity is strong. The observations include many 3-hour periods with different $V(x)$ and shear wave energies, whereas the simulations are for conditions during two particular 3-hour periods, so only qualitative correspondence is possible.

shear wave energy production by the mean flow is greater than shear wave energy dissipation $(P / D>1)$ in a narrow region around $\chi \approx 0.5$ (immediately seaward of $V_{\max }$ ), and production is positive but less than dissipation $(0<P / D<1)$ in the remainder of the region where $0<\chi<1$. Shear waves return energy to the mean flow $(P<0)$ far offshore of $V_{\max }$ where $V$ is weak $(\chi>1)$.

\section{Comparison of Case Examples With Linear Stability Theory}

\subsection{Stability Theory Review}

[27] The time-averaged (over incident wave periods) shallow-water equations with a rigid lid, alongshore uniform depth $h(x)$, and linearized bottom drag (equation (10)), yield the potential vorticity equation

$$
\left(\partial_{t}+V \partial_{y}+\frac{\mu}{h}\right)\left(\left(\frac{\psi_{x}}{h}\right)_{x}+\frac{\psi_{y y}}{h}\right)-\psi_{y}\left(\frac{V_{x}}{h}\right)_{x}-\frac{\mu h_{x}}{h^{3}} \psi_{x}=0
$$

where $\psi$ is the stream function $\left(h u=-\psi_{y}\right.$ and $\left.h v=\psi_{x}\right)$ of the (shear wave) perturbation velocities $(u, v)$. Assuming plane wave solutions $\psi(x, y, t)=\operatorname{Re}\{\hat{\psi}(k, x) \exp [(i \kappa(y-$ $c t))]\}$ with alongshore radial wave number $\kappa=2 \pi k$ yields the generalized eigenvalue problem

$$
\left(V-c-\frac{i \mu}{\kappa h}\right)\left(\left(\frac{\hat{\psi}_{x}}{h}\right)_{x}-\kappa^{2} \frac{\hat{\psi}}{h}\right)-\hat{\psi}\left(\frac{V_{x}}{h}\right)_{x}+\frac{i \mu h_{x}}{\kappa h^{3}} \hat{\psi}_{x}=0
$$

for the eigenvalues $c$ and eigenfunctions $\hat{\psi}(k, x)$ at each $\kappa$ [Dodd et al., 1992]. The phase speed and growth rate of a linear mode are $\operatorname{Re}\{c\}$ and $\operatorname{Im}\{\kappa c\}$, respectively, where $\operatorname{Im}\{\kappa c\}>0$ for unstable (growing) modes. The phase speed of an unstable mode $\left(C_{\text {unstable }}\right)$ is equal to $V$ at a mean potential vorticity $V_{x} / h$ extremum if dissipation and mixing are neglected, and $C_{\text {unstable }}$ is reduced only slightly for realistic values of drag and eddy viscosity. Estimates of $V$, $V_{x}$, and $V_{x x}$ used in equation (13) were obtained with cubic splines that minimize the root mean square curvature $V_{x x}$ and fit the observed $V$ within a specified tolerance [de Boor, 1978]. At each wave number there are many modes, but never more than one unstable mode, because the curvatureminimizing, spline fit $V(x)$ produces only a single PV extremum, which is located on the seaward side of the mean current maximum. Solutions to the eigenvalue problem equation (13), obtained with a finite difference scheme, do not depend strongly on the somewhat arbitrary boundary conditions of $V=0$ both at the shoreline and far offshore (Appendix D).

[28] The interpretation of the results from the linear stability analysis using the observed $V$ is complicated by shear wave mixing that alters the mean current $V$ from its initial (preshear wave) values. However, $V$ without shear wave mixing is not known, and instabilities can be suppressed by increasing the amount of model eddy mixing (from sources other than shear waves), or enhanced by reducing the eddy mixing [Özkan-Haller and Kirby, 1999]. For example, compared with the instabilities of the observed $V(x)$, instabilities of a model $V(x)$ with no eddy mixing (Appendix C) have larger (as much as a factor of 10) maximum growth rates and a much wider range of unstable wave numbers. Additionally, there are multiple unstable modes (frequencies) for each $k$. Given the difficulty of modeling $V(x)$ accurately in the absence of shear waves, the observed $V(x)$ was used. A case example with energetic shear waves, and a weakly sheared observed $V(x)$ that is only marginally unstable, is discussed in section 4.5.

[29] The maximum mean alongshore current $V_{\max }$ and seaward shear $V_{x}$ on 2 October are roughly twice the values on 28 August, and the maximum growth rate on 2 October also is about double the 28 August maximum growth rate. However, the wave number of the fastest growing mode $\left(\approx 0.006 \mathrm{~m}^{-1}\right)$ and the range of unstable wave numbers $\left(\approx 0.001-0.01 \mathrm{~m}^{-1}\right)$ are similar (Figure 12). The unstable modes ( $f / k$ indicated with circles in Figures 2 and 3 ) are approximately nondispersive with $C_{\text {unstable }}$ equal to about $0.7 V_{\max }$.

\subsection{Phase Speed}

[30] The phase speeds $C_{\text {unstable predicted for the theo- }}$ retically unstable modes on 2 October and 28 August are 


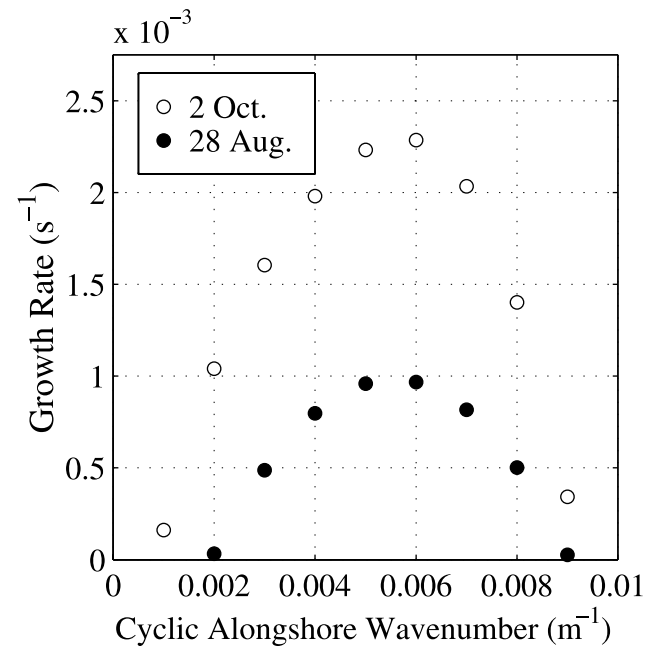

Figure 12. Growth rates of linearly unstable modes versus cyclic alongshore wave number for 28 August (solid circles) and 2 October (open circles). The dispersion relations of the unstable modes are shown with open circles in Figures 2 and 3. The growth rates are based on spline fit $V(x)$ (Figure 4b). On 28 August and 2 October the maximum mean seaward shears are 0.028 and $0.044 \mathrm{~s}^{-1}$, respectively, and the bottom drag parameters are $\mu=0.0008$ and $0.0010 \mathrm{~m} \mathrm{~s}^{-1}$, respectively.

similar to $C^{u}$ observed near the shoreline (e.g., the dashed lines are close to the circles in Figures 3a, 3c, 4a, and 4c), similar to previous observations near $V_{\max }$ [Dodd et al., 1992]. On both days, $V$ at array 2 is substantially less than $V$ at array 1 (Figure $4 \mathrm{~b}$ and the dark solid lines in Figures $2 \mathrm{a}, 2 \mathrm{c}$, $3 \mathrm{a}$, and $3 \mathrm{c}$ ), whereas the observed $C^{u}$ decrease by a smaller fraction and remain relatively close to the $k$ - $f$ of the unstable modes. Farther offshore at arrays 3, 4, and 5, shear wave RMS velocity fluctuations $q_{\mathrm{sw}}$ are less (and sometimes much less) than $1 / 4$ of the values at array 1 (Figure $4 \mathrm{c}$ ). At the offshore arrays on 28 August, $q_{\mathrm{sw}}$ are low $\left(<2 \mathrm{~cm} \mathrm{~s}^{-1}\right)$, $E^{u, v}(k, f)$ lack a well-defined ridge (e.g., Figure 3e), and shear wave properties cannot be estimated accurately. On 2 October, a nondispersive ridge in $E^{u}(k, f)$ is present at all 5 arrays. At array 5 (Figure $2 \mathrm{e}$ ), $C^{u} \approx-35 \mathrm{~cm} \mathrm{~s}^{-1}$ is less than $1 / 2$ of $C^{u}$ at array $1\left(\approx-90 \mathrm{~cm} \mathrm{~s}^{-1}\right)$ and of the unstable modes $\left(\approx-88 \mathrm{~cm} \mathrm{~s}^{-1}\right)$, but is close to the local $V(\approx-25 \mathrm{~cm}$ $\left.\mathrm{s}^{-1}\right)$. Other cases with $V$ a narrow shoreline jet are similar. Near the shoreline, where $V$ is strongest, $C_{\text {unstable }} \approx C^{u} \approx V$, similar to Dodd et al. [1992]. Farther offshore, where the energy of the unstable mode has decayed significantly and $V$ also is reduced, slower propagating oscillations with relatively low energy are observed, again with $C^{u} \approx V$. The correlation between $C^{u}$ and $V$ (Figure 9) is reduced by the tendency of $C^{u}$ observed at arrays 1 and 2 to remain close to $C_{\text {unstable }}$ even when $V$ varied substantially between these arrays. Occasionally, differences in $C^{u}$ and $C^{v}$ at the same array suggest the simultaneous presence of fast and slow moving oscillations at a single cross-shore position. The origin of the slow moving oscillations, with $C$ less than unstable modes and approximately equal to the local $V$, is unclear. Perhaps eddies or other features propagate offshore and are advected past the deep arrays by the relatively weak and unsheared $V$.

\subsection{Cross-Shore Variation of Energy Levels}

[31] The cross-shore velocity frequency spectra $E_{s w}^{u}(f)$ near the shore (e.g., arrays 1 and 2) are maximum at roughly the frequency of the fastest growing mode on both 2 October and 28 August $(0.0046 \mathrm{~Hz}$ in Figures $2 \mathrm{~b}$ and $2 \mathrm{~d}$ and $0.0016 \mathrm{~Hz}$ in Figures $3 \mathrm{~b}$ and $3 \mathrm{~d}$ ). Although the observed ridges sometimes extended beyond the range of theoretically unstable wave numbers, shear wave energy was relatively low at stable wave numbers (e.g., $|k|>0.01 \mathrm{~m}^{-1}$ in Figures $3 a$ and $3 b$ ).

[32] The cross-shore structure of $|\hat{u}|^{2}$ and $|\hat{v}|^{2}$ of two unstable modes, the fastest growing mode and a lower $(k, f)$ mode, are similar to the structure of the observed $E^{u, k}(k, f)$ on 2 October and 28 August (Figure 13). The $(k, f)$ of these modes are within the observed nondispersive ridges at arrays 1 and $2(\otimes$ in Figures 2a, 2c, 3a, and 3c). On both days, for both $k$, and for both $u$ and $v$, the predicted and observed cross-shore decay between arrays 1, 2, and 3 is strong (Figure 13). The observed decay between arrays 3, 4, and 5 is less than predicted. However, $E(k, f)$ at these unstable $k-f$ is low at the offshore arrays, and may be overestimated because of leakage from the more energetic, theoretically stable $k-f$ with $C \approx V$ (Figure $2 \mathrm{e}$ ) and from gravity waves. The rough agreement between the crossshore structure of eigenfunctions of unstable $(k, f)$ and observed $E^{u, v}(k, f)$ in these examples is typical of other cases with a narrow $V(x)$ that is maximum near the shoreline (e.g., 24 September; Figure 1).

[33] The agreement of observations with the cross-shore structure of linear eigenfunctions was improved by integrating (in frequency and wave number) over the entire ridge (Figure 14), probably owing to both the higher degrees of freedom obtained when many $E(k, f)$ were combined, and to systematic cancellation between errors at high and low frequencies (not shown).

[34] Although the strong cross-shore decay in observed $E^{u, v}(k, f)$ and ridge-integrated variance agree qualitatively with the cross-shore structure of unstable modes, differences can be substantial. For example, at array 1 on 2 October, $v_{r m s}$ is underestimated and $u_{r m s}$ is overestimated, each by roughly $50 \%$ (Figure 14a). Differences of this size are expected owing to the sensitivity of the theoretical $\hat{v}$ to unmeasured detail in $V(x)$ (Appendix D). Cases with weaker $V$ (and presumably weaker shear wave mixing) than 28 August could not be compared with linear stability theory because the shear wave ridges in $E^{u, v}(k, f)$ do not extend beyond the first frequency bin $(\leq 0.0011 \mathrm{~Hz})$, and the structure of $V(x)$ within the narrow surf zone is not resolved by the cross-shore array.

\subsection{Cross-Shore Variation of Phases}

[35] Phase differences between velocity time series observed at different cross-shore locations are similar to predictions using the linearly unstable modes. On 28 August, the predicted and observed $u$ at arrays 2 and 3 are in phase at all shear wave dominated $f$ (triangles in Figure 15b), whereas the phases between $u$ at arrays 1 and 2 are frequency dependent (circles in Figure 15b). Phase relationships are similar for $v$ (Figure 15d). 


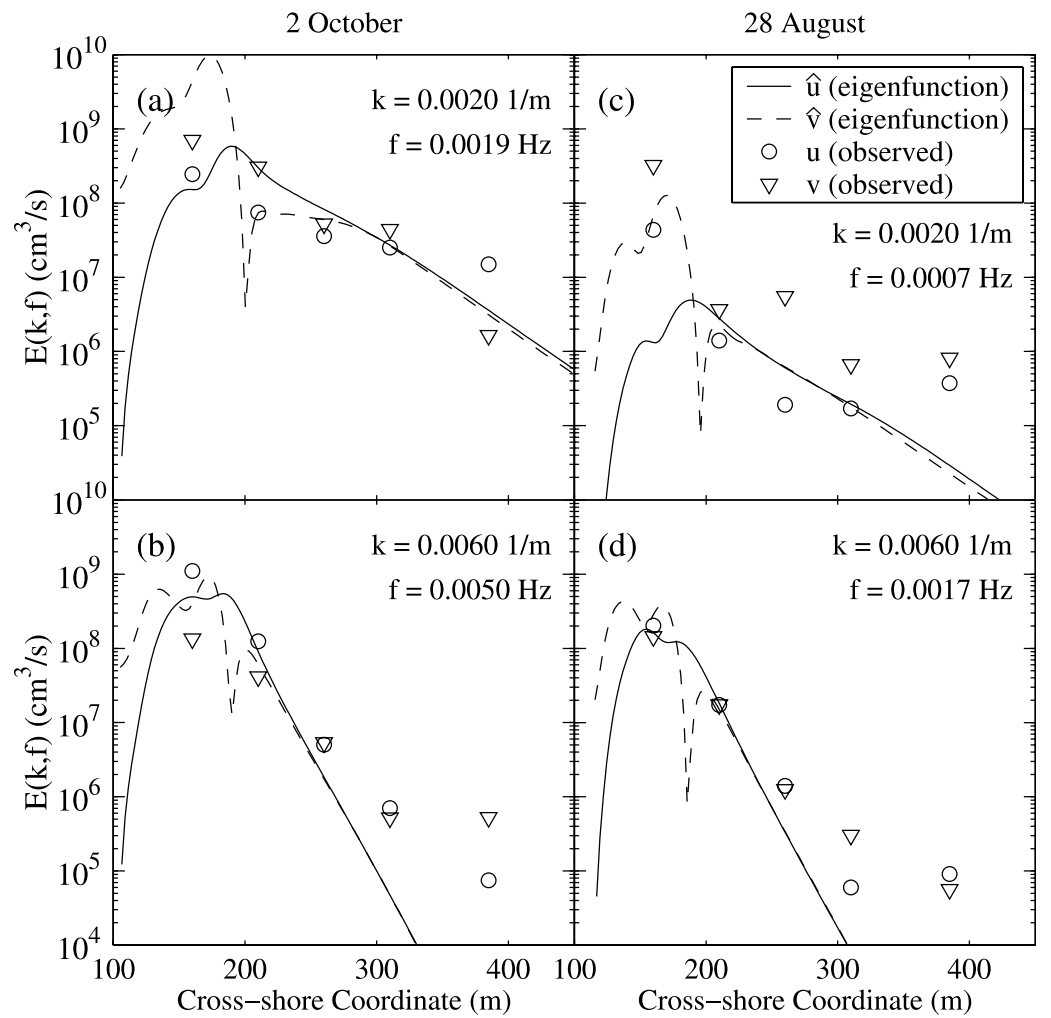

Figure 13. Observed (symbols) and modeled (curves) alongshore wave number-frequency spectra $E(k, f)$ for $u$ and $v$ (see legend) versus the cross-shore coordinate on (left) 2 October for (a) $k=0.002 \mathrm{~m}^{-1}, f=$ $0.0019 \mathrm{~Hz}$, and (b) $k=0.006 \mathrm{~m}^{-1}, f=0.0050 \mathrm{~Hz}$, and on (right) 28 August for (c) $k=0.002 \mathrm{~m}^{-1}, f=$ $0.0007 \mathrm{~Hz}$, and (d) $k=0.006 \mathrm{~m}^{-1}, f=0.0017 \mathrm{~Hz}$. These $(k, f)$ are indicated with crossed circles in Figure 2 (2 October) and Figure 3 (28 August). Linear eigenfunctions $|\hat{u}(k, x)|^{2}$ (solid curves) and $|\hat{v}(k, x)|^{2}($ dashed curves) are shown, where at each $(k, f)$ the eigenfunction amplitude is selected so that $|\hat{u}|^{2}+|\hat{v}|^{2}$ equals the total variance density $E^{u}(k, f)+E^{v}(k, f)$ observed at array 2 . The sharp dips in the $v$ eigenfunctions correspond to locations where $v$ reverses sign $(\times$ in Figure 16$)$.

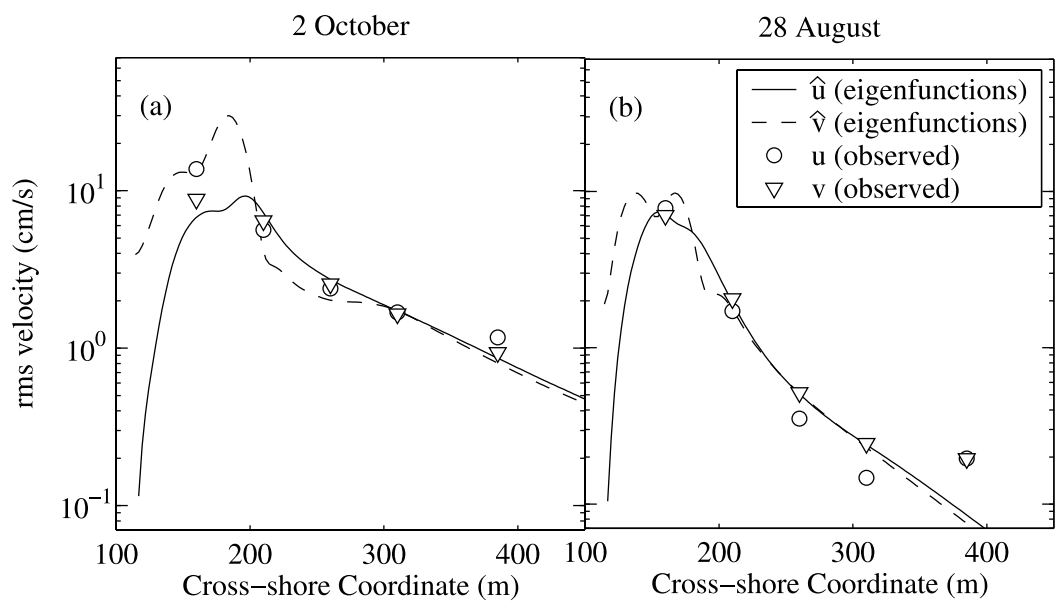

Figure 14. Observed (symbols) and modeled (curves) shear wave ridge rms velocity fluctuations versus cross-shore distance for (a) 2 October and (b) 28 August for $u$ and $v$ velocity components (see legend). The observed ridge frequency spectra $E_{\text {ridge }}^{u}(f)$ and $E_{\text {ridge }}^{v}(f)$ is obtained by integrating $E^{u}(k, f)$ and $E^{v}(k, f)$, respectively, over the range of wave numbers $\left(2 f / C<|k|<f / C+0.01 \mathrm{~m}^{-1}\right)$ corresponding to ridges with $C \approx-90 \mathrm{~cm} \mathrm{~s}^{-1}$ (2 October; Figure 2) and $C \approx 30 \mathrm{~cm} \mathrm{~s}^{-1}$ (28 August; Figure 3 ). The $k-f$ integration range for a particular ridge is the same for $u$ and $v$ and at all cross-shore locations. At each $f$ the eigenfunction amplitude is selected so that the modeled $|\hat{u}(f)|^{2}+|\hat{v}(f)|^{2}$ equals $E_{\text {ridge }}^{u}(f)+E_{\text {ridge }}^{v}(f)$ at array 2 . The observed and eigenfunction-modeled total ( $k-f$ integrated) ridge variance (rms is plotted) are obtained by integrating $E_{\text {ridge }}(f)$ and $|\hat{u}(f)|^{2}+|\hat{v}(f)|^{2}$, respectively, over theoretically unstable frequencies ( $f \leq 0.009 \mathrm{~Hz}$ ). 


\section{Cross-shore-separated u}
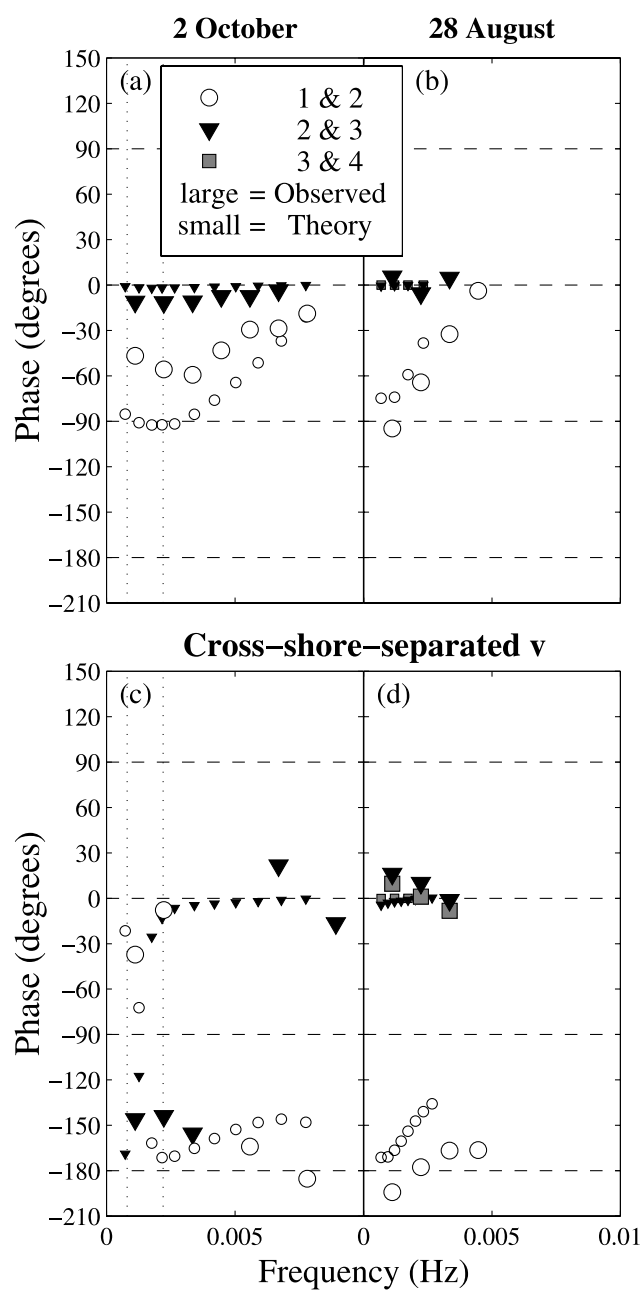

Figure 15. Phase difference between cross-shore-separated observations of (a) and (b) cross-shore $u$ and (c) and (d) alongshore $v$ velocity components versus frequency for (left) 2 October and (right) 28 August. Observations (large symbols; see legend) are based on cross-spectra between pairs of sensors at the same alongshore location in adjacent alongshore arrays (see legend), averaged over the array pairs. When all six sensors are operational in both arrays, the averaged cross-spectra have 138 degrees of freedom (assuming independent cross spectra), and the associated phase differences have standard deviations of roughly $10^{\circ}-$ $20^{\circ}$, depending on the coherence. Observed phases are shown only if the coherence is significant at the $80 \%$ confidence level and only for the frequency band that is shear wave dominated at both arrays $\left(f<f_{\text {upper, }}\right.$ where $f_{\text {upper }}$ is the highest $f$ for which $\left.E_{s w}^{u, v}(f) / E^{u, v}(f)>2 / 3\right)$. Phase differences of unstable modes (small symbols; see legend) are shown for 2 October and 28 August with higherfrequency resolution than the observations. Stream functions for the $f$ indicated with vertical dotted lines on 2 October are shown in Figure 16.

[36] On 2 October, $|V|$ and $q_{s w}$ were larger than on 28 August (Figure 1), and the qualitative agreement between the observed and theoretical phase differences extends to higher frequencies (Figures 15a and 15c). The centers of the circulation cells (where $v$ reverses sign, $\mathrm{x}$ in Figure 16) of linearly unstable shear wave modes move shoreward from offshore to onshore of array 2, as the frequency increases from 0.0008 to $0.0022 \mathrm{~Hz}$ (compare Figure 16a with Figure 16b), because the cell alongshore $(k=f / c)$ and cross-shore spatial scales decrease with increasing frequency. Therefore the theoretical relative phase between $v$ at array 2 and 3 changes from $\approx 180^{\circ}$ (at $0.0008 \mathrm{~Hz}$ ) to $0^{\circ}$ (at $0.0022 \mathrm{~Hz}$ ) (small triangles in Figure $15 \mathrm{c}$ ), whereas the phase between $v$ at arrays 1 and 2 changes from $\approx 0^{\circ}$ to $180^{\circ}$ (small circles in Figure $15 \mathrm{c}$ ). The observed phase differences (large circles and triangles in Figure 15c) vary similarly, although the $180^{\circ}$ phase change occurs at higher frequency than predicted. The coherence (not shown) is low at frequencies where the phase difference varies substantially over the $0.0011 \mathrm{~Hz}$ observational bandwidth. Observed phase differences between colocated observations of $u$ and $v$ also resemble the phases of the linearly unstable modes [Noyes, 2002].

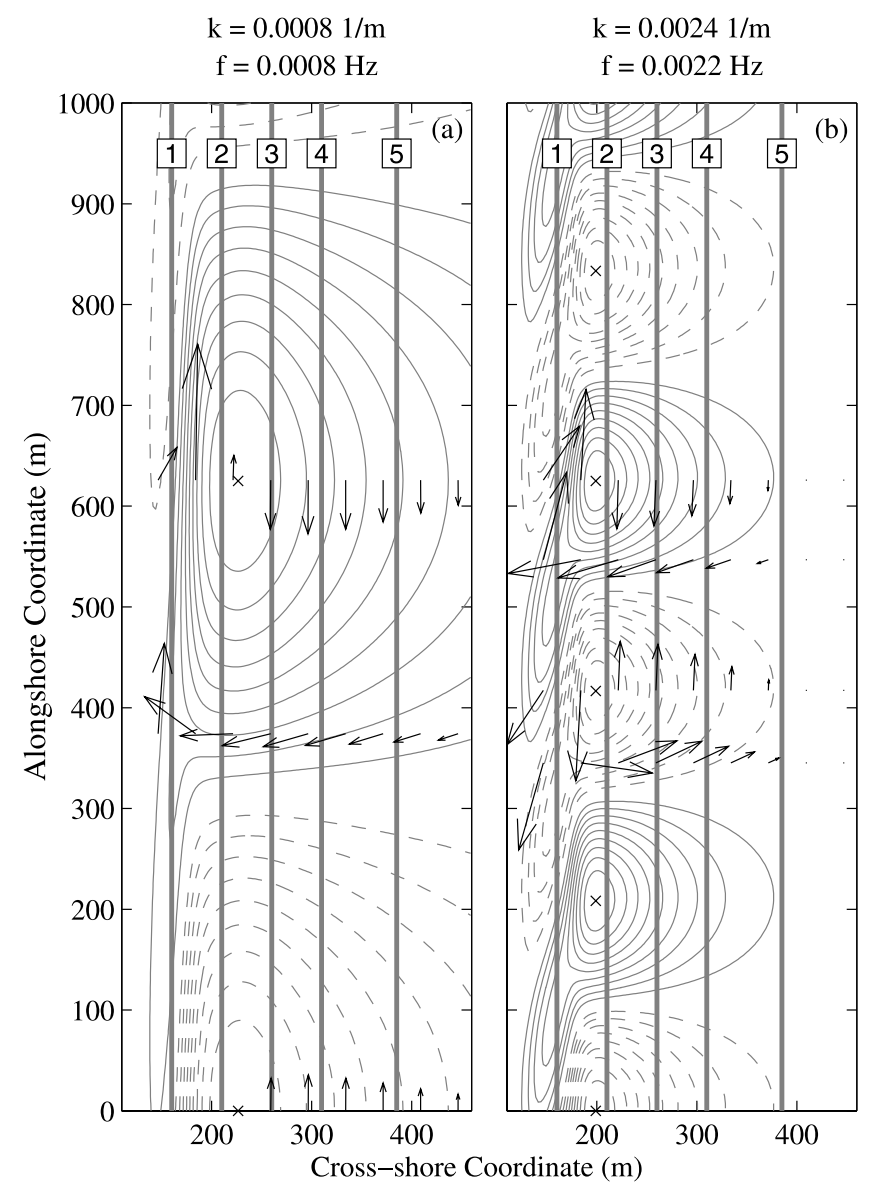

Figure 16. Stream functions of linearly unstable modes on 2 October with (a) $k=0.0008 \mathrm{~m}^{-1}, f=0.0008 \mathrm{~Hz}$, and (b) $k=0.0024 \mathrm{~m}^{-1}, f=0.0022 \mathrm{~Hz}$. Solid and dashed curves indicate clockwise and counterclockwise rotation, respectively. The vertical shaded lines indicate the cross-shore locations of alongshore arrays (array numbers are in boxes). The direction of the arrows indicates the direction of the local flow, and the arrow length depends logarithmically on the flow magnitude. 

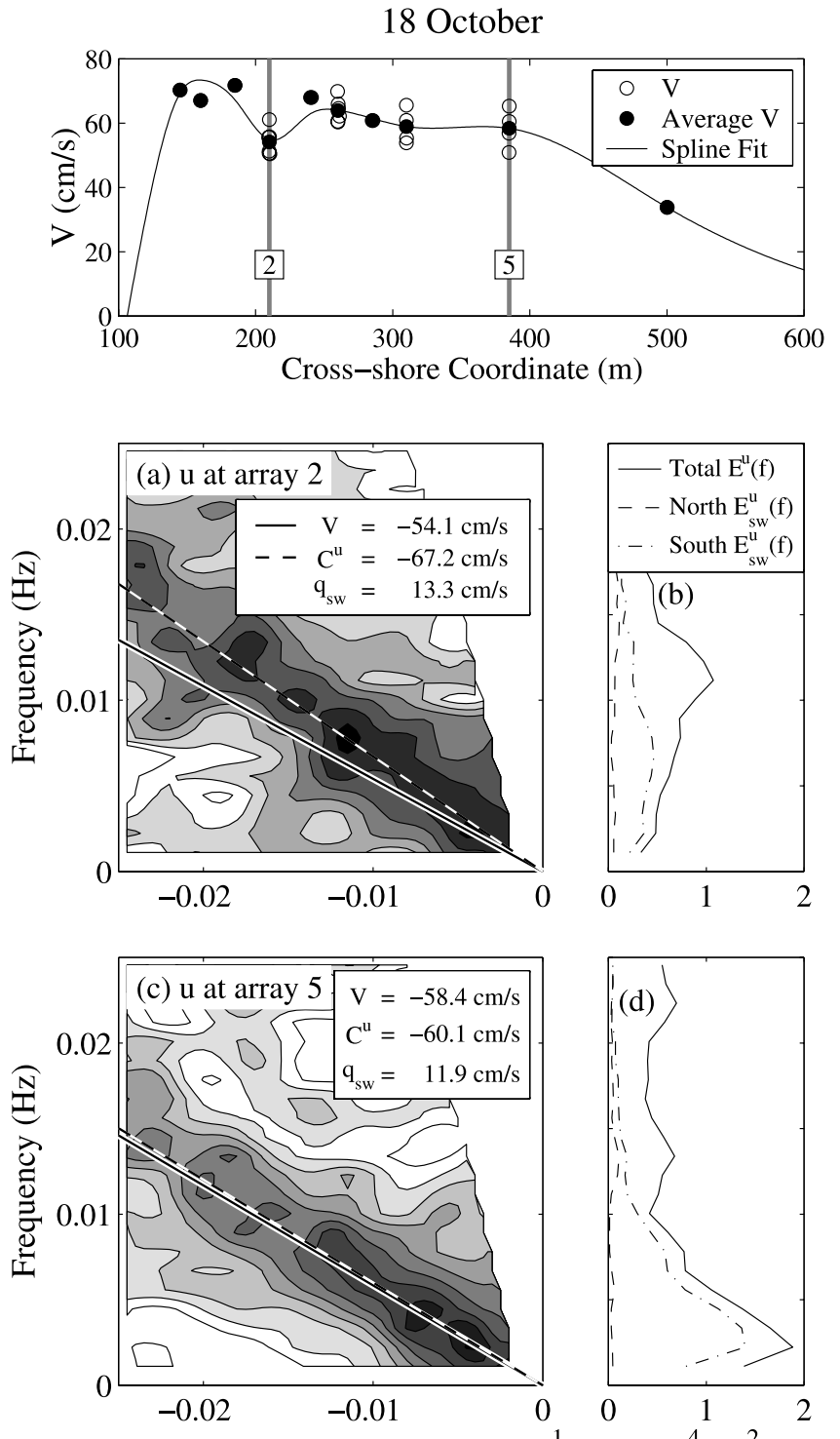

Cyclic Alongshore Wavenumber $\left(\mathrm{m}^{-1}\right) \quad \times 10^{4} \mathrm{~cm}^{2} / \mathrm{s}$

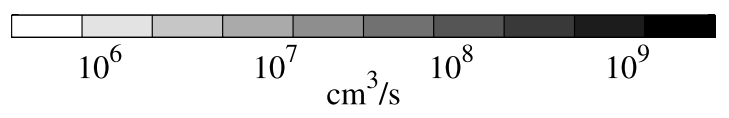

Figure 17. For 1600-1900 EST, 18 October 1997, (top) mean alongshore current $V$ versus the cross-shore coordinate. At cross-shore coordinates corresponding to an alongshore array, individual observed $V$ (open circles) are averaged together (solid circles). Coastal buoyancy currents, identified by the passage of a strong salinity front [Lentz et al., 2003], may contribute to $V$. Alongshore wave numberfrequency spectra of shear wave cross-shore velocity $E^{u}(k, f)$ obtained from observations at alongshore arrays (a) 2 and (c) 5 are shown for southward propagating shear waves. (b) and (d) For each array, frequency spectra of northward (dashed curve) and southward (dotted curve) propagating shear waves and the total (shear plus gravity waves, solid curve) frequency spectrum. The format is similar to Figures 2 and 3.
[37] Propagating patterns observed in the flow field (Appendix A) on 2 October have cross- and alongshore spatial structures similar to the structure of the stream function of the unstable mode $(f \approx 0.0022 \mathrm{~Hz}$ is shown in Figures $5 \mathrm{a}$ and $5 \mathrm{~b}$ for observations and in Figure $16 \mathrm{~b}$ for unstable modes). The circulation cells observed at higher frequency $(0.0039-0.0050 \mathrm{~Hz})$ are smaller and centered closer to the shoreline (compare Figures $5 \mathrm{a}$ and $5 \mathrm{~b}$ with Figures $5 \mathrm{c}$ and $5 \mathrm{~d}$ ), similar to decreases in the spatial scale of linearly unstable modes with increasing frequency (Figure 16). Smaller circulation cells at even higher frequency are not resolved with the typically $>50 \mathrm{~m}$ spacing between adjacent arrays.

\subsection{Anomalous Case With Strong $\boldsymbol{V}$ and Weak $\boldsymbol{V}_{\boldsymbol{x}}$}

[38] Linear stability theory agrees qualitatively with the observations on 2 October, 28 August, and other cases with $V$ a shoreline jet (not shown). However, linear stability theory (using the observed $V(x)$ ) failed in a few cases when $V(x)$ was strong $\left(>50 \mathrm{~cm} \mathrm{~s}^{-1}\right)$, but weakly sheared over the cross-shore transect. For example, the broad mean alongshore current $V(x)$ on 18 October (Figure 17) is unstable only for a narrow band (compared with 2 October and 28 August; Figure 12) around $k \approx 0.002 \mathrm{~m}^{-1}$, and the maximum growth rate of the linear modes is $<10^{-4} \mathrm{~s}^{-1}$, compared with $\mathrm{O}\left(10^{-3} \mathrm{~s}^{-1}\right)$. Despite the low $V_{x}$, shear wave ridges with relatively high energy levels are observed over a wide frequency band at all arrays (Figures 17a and 17c). Shear wave RMS velocity fluctuations are larger on 18 October at array $5\left(q_{\mathrm{sw}}=11.9 \mathrm{~cm} \mathrm{~s}^{-1}\right)$ than on 2 October at array $2\left(q_{\mathrm{sw}}=8.6 \mathrm{~cm} \mathrm{~s}^{-1}\right)$. The dominant CEOF at an energetic shear wave frequency spans the entire cross-shore transect (Figure 18), and has an alongshore propagation speed similar to the observed $V$.

[39] Several factors may contribute to the simultaneous occurrence of weak current shear and high shear wave

\section{October}

CEOF \#1 of $0.0017-0.0028 \mathrm{~Hz}$ (33\% of the variance)

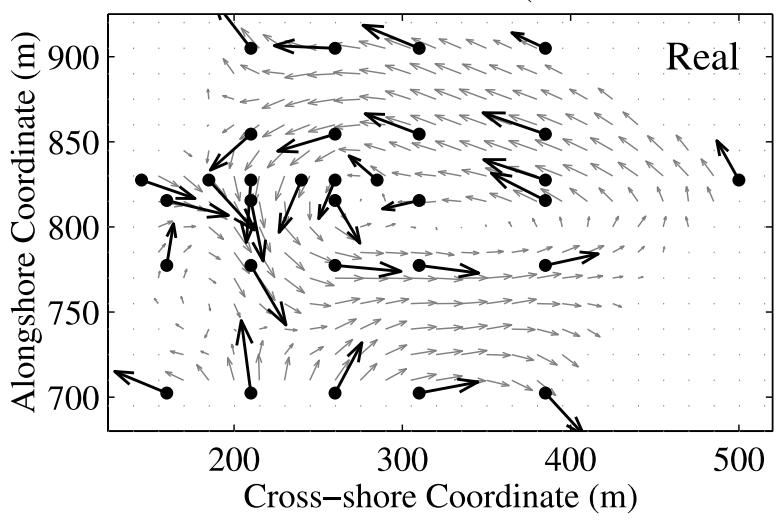

Figure 18. Dominant velocity CEOF spatial pattern (Appendix A1) of the frequency band $0.0017-0.0028 \mathrm{~Hz}$ on 18 October, near the spectral peak at array 5 (Figure 16). The format is the same as Figure 3, except that only the real part is shown. Combination of the real and imaginary parts at different phases of a shear wave cycle shows circulation cells propagating alongshore at about $55 \mathrm{~cm} \mathrm{~s}^{-1}$. 
energy. The observed $V$, used in the present stability analysis, may be smoothed by shear wave mixing. Numerical models indicate that $V(x)$ with shear wave mixing included may be stable, whereas the initial $V(x)$ without shear wave mixing is unstable [Slinn et al., 1998]. Instabilities using a model $V(x)$ (Appendix $C$ ) are much stronger than with the observed $V(x)$, but the accuracy of the model is unknown. Additional factors may affect the stability analysis. For example, the 3-hour record length (required for adequate stability and frequency resolution of $E(k, f)$ ) likely reduces the estimated shear $V_{x}$ by averaging together $V(x)$ profiles that are changing in response to tidal variations in water depth [Thornton and Kim, 1993]. If the cross-shore location of $V_{\max }$ varies over the 3-hour averaging time, then the 3-hour-averaged $V$ will be smoother (smaller $V_{x}$ ) than it would be for shorter time averages of $V$. Additionally, $V(x)$ is assumed steady in the stability analysis, but temporal variation of $V$ can increase the strength of instabilities substantially [Pedlovsky and Thomson, 2003].

\section{Summary}

[40] Shear wave properties were estimated with 5 alongshore arrays of current meters deployed between 50 and $300 \mathrm{~m}$ from the shoreline of a sandy beach. Nondispersive ridges of elevated energy often were present in alongshore wave number-frequency spectra $E(k, f)$ of cross-shore and alongshore velocity fluctuations, especially close to the shoreline where the mean alongshore current $V$ usually was strongest. Pressure fluctuations associated with shear waves were small, consistent with the rigid lid approximation. Shear wave rms cross-shore velocities were about $20 \%$ larger than RMS alongshore velocities, and total (sum of both velocity components) RMS shear wave fluctuations were between $10-40 \%$ of $V$. The observations suggest that shear waves are generated primarily in the highly sheared region immediately seaward of the location of the maximum mean alongshore current $V_{\max }$, and that elsewhere net energy losses, resulting from dissipation and energy transfers back to the mean flow, exceed shear wave energy production.

[41] In case examples of narrow alongshore current jets with $V_{\max }$ located near the shoreline, shear wave energy was maximum near the shoreline, and concentrated at $(k, f)$ near those expected for nondispersive, linearly unstable modes. At these $(k, f)$, the strong cross-shore decay of $E(k, f)$ and the observed cross-shore phase variation of shear wave velocity fluctuations also are similar to the structure predicted for the linearly unstable modes. A shear wave ridge with a slower, theoretically stable phase speed $(\approx$ the local $V)$ was sometimes observed at the deeper arrays where the linearly unstable modes are attenuated strongly. Shear wave energy levels also were high for a few cases with strong, but weakly sheared, mean alongshore currents.

\section{Appendix A: CEOF Analysis}

[42] Following Horel [1984], the observed time series of cross-shore $u(\vec{x}, t)$ and alongshore $v(\vec{x}, t)$ velocity are extended by addition of a complex part equal to their Hilbert transforms $(\breve{u}(\vec{x}, t)$ and $\check{v}(\vec{x}, t))$, forming complex time series $\xi(t)$

$$
\left(\begin{array}{c}
\xi_{1}(t) \\
\xi_{2}(t) \\
\vdots \\
\xi_{N}(t) \\
\xi_{N+1}(t) \\
\xi_{N+2}(t) \\
\vdots
\end{array}\right)=\left(\begin{array}{c}
u\left(\vec{x}_{1}, t\right)+i \check{u}\left(\vec{x}_{1}, t\right) \\
\left(\vec{x}_{2}, t\right)+i \check{u}\left(\vec{x}_{2}, t\right) \\
\vdots \\
\left(\vec{x}_{N}, t\right)+i \check{u}\left(\vec{x}_{N}, t\right) \\
\left(\vec{x}_{1}, t\right)+i \check{v}\left(\vec{x}_{1}, t\right) \\
\left(\vec{x}_{2}, t\right)+i \check{v}\left(\vec{x}_{2}, t\right) \\
\vdots
\end{array}\right)
$$

where the $\mathrm{N}$ current meters have locations $\vec{x}_{i}$. The Hilbert transforms, the original time series phase shifted by $90^{\circ}$, were calculated from Fourier transforms of time series that were cosine tapered for the first and last $10 \%$ of the series to reduce end effects.

[43] With $\xi_{i}(t)=\sum_{j=1}^{2 N} A_{j}(t) B_{i, j}^{*}$, and uncorrelated temporal functions $A_{j}(t)$, the orthonormal spatial functions $B_{i, j}$ $\left(\sum B_{m, i} B_{m, j}^{*}=\delta_{i j}\right)$ are the eigenvectors of the $(2 \mathrm{~N}$ by $2 \mathrm{~N})$ covariance matrix of the complex time series $C_{i, j}=$ $\left\langle\xi_{i}(t)^{*} \xi_{j}(t)\right\rangle$. The eigenvalue $\lambda_{n}$ of the $n$th CEOF is the portion of the total variance of all the time series attributable to the CEOF.

[44] Phase differences can change rapidly with frequency (e.g., Figure 15c), and a wide frequency bandwidth reduces the coherence and CEOF eigenvalues. Therefore covariance matrices are based on narrow $(0.0011-\mathrm{Hz})$ frequency bands. The complex temporal functions $A_{j}(t)$ can be written as $A_{j}(t)=a_{j}(t) e^{-i \phi_{j}(t)}$, where $a_{j}(t)$ and $\phi_{j}(t)$ are real temporal amplitude and phases, respectively. Time series of velocity at $\vec{x}_{i}$ are

$$
\begin{gathered}
u\left(\vec{x}_{i}, t\right)=\operatorname{Re}\left\{\xi_{i}(t)\right\} \\
=\sum_{j=1}^{N} a_{j}(t)\left(\cos \phi_{j}(t) \operatorname{Re}\left\{B_{i, j}\right\}+\sin \phi_{j}(t) \operatorname{Im}\left\{B_{i, j}\right\}\right)
\end{gathered}
$$

and similarly for $v$. In Figures 5 and 18, the orientation and length of the bold arrows indicate the direction and magnitude of the real (left panels) and imaginary (right panels) parts of the spatial functions $B_{i, j}$, which represent the vector velocity $(u, v)$ at $\vec{x}_{i}$ at temporal phases differing by $90^{\circ}$.

\section{Appendix B: Data Set for Statistical Analysis}

[45] On the basis of tests of the array resolution with synthetic cross spectra (not shown), an alongshore array was defined as operational for a particular 3-hour period if there were at least 5 functioning current meters, including the pair with the shortest alongshore lag $(12 \mathrm{~m})$. Array 1 was operational for 3653 -hour periods, less than the other arrays (approximately 800 3-hour periods each). Ridges usually were not defined (or absent) (e.g., Figure 3e) when the array-estimated shear wave energy was low. To elimi- 
nate these cases from the statistical analysis (section 3), estimates from an array are excluded if the shear wave RMS flow speed $q_{\mathrm{sw}}<3 \mathrm{~cm} \mathrm{~s}^{-1}$, or if $E(k, f)$ does not indicate at least twice as much non-gravity wave energy propagating in one alongshore direction as in the other direction in the $0.00165-0.025-\mathrm{Hz}$ frequency band. In most excluded cases (e.g., Figure 3e), $V$ is weak and a ridge is not evident [Noyes et al., 2002]. In a few excluded cases, a ridge is present, but the ratio of upcoast to downcoast energy is below the arbitrary criteria of 2 (e.g., the ratio is 1.8 at array 5 on 2 October; Figure 2e). Occasionally, data from all 5 arrays are included, but more often only one or two shallow arrays met the criteria (e.g., 28 August and 24 September; Figures $4 \mathrm{c}$ and $4 \mathrm{~d})$. A total of 781 3-hour array runs are retained $(189,266,184,87$, and 69 runs from arrays 1 through 5 , respectively). Less than $10 \%$ of the more than 800 available runs are retained at the offshore arrays 4 and 5 , because $q_{\text {sw }}$ usually was below the $3 \mathrm{~cm} \mathrm{~s}^{-1}$ threshold (Figure 6d). In contrast, more than half of the 333 available 3-hour runs at the shallowest array are retained.

\section{Appendix C: Estimation of $\boldsymbol{V}_{\boldsymbol{x}}$}

[46] The growth rates of linearly unstable modes depend on the mean current shear $V_{x}$ [Bowen and Holman, 1989]. For a narrow, shoreline-intensified jet typical of these observations, the growth rates depend primarily on the shear on the seaward side of the jet, because instabilities arising from the shear on the shoreward side of the jet are suppressed by the nearby shoreline boundary. Numerical studies suggest that mixing by finite amplitude shear waves can alter the original mean current profile $V(x)$ significantly, and that the growth rates of the linear modes of $V(x)$ after shear waves develop can be much less than the growth rates of the modes of the original $V(x)$ without shear wave mixing [e.g., Slinn et al., 1998; Özkan-Haller and Kirby, 1999]. Therefore estimates of both the observed ( $V_{x}^{\text {obs }}$, includes shear wave mixing) and modeled $\left(V_{x}^{\text {model }}\right.$, no shear wave mixing) maximum mean shear on the seaward side of the mean current jet were compared with $q_{\mathrm{sw}}$.

[47] The maximum observed cross-shore shear $\left|V_{x}^{\text {obs }}\right|$ was estimated crudely from second-order finite differences of the mean alongshore current $V$ observed at adjacent crossshore locations. Following Howd et al. [1991], the model shear was calculated using a one-dimensional wave transformation model to estimate radiation stresses, and a balance between the cross-shore gradient of the radiation stresses and linear bottom drag. The predicted $V(x)$ sometimes are bimodal, and $V_{x}^{\text {model }}$ is estimated as the maximum seaward shear offshore of the "bar" (first maxima in the bathymetry seaward of the shoreline). Both $\left|V_{x}^{\text {obs }}\right|$ and $\left|V_{x}^{\text {model }}\right|$ are correlated with $q_{\mathrm{sw}}(r=0.64$ and 0.47 , respectively) at array 1 , and are uncorrelated farther offshore. Correlations are similar using other measures of $V_{x}^{\text {model }}$ (e.g., the maximum shear on the shoreward face of the seaward jet, rather than on the seaward face).

\section{Appendix D: Numerical Solutions of the Linear Stability Equation}

[48] The linearized potential vorticity equation (13), an eigenvalue problem for $c$, was solved following Allen et al.
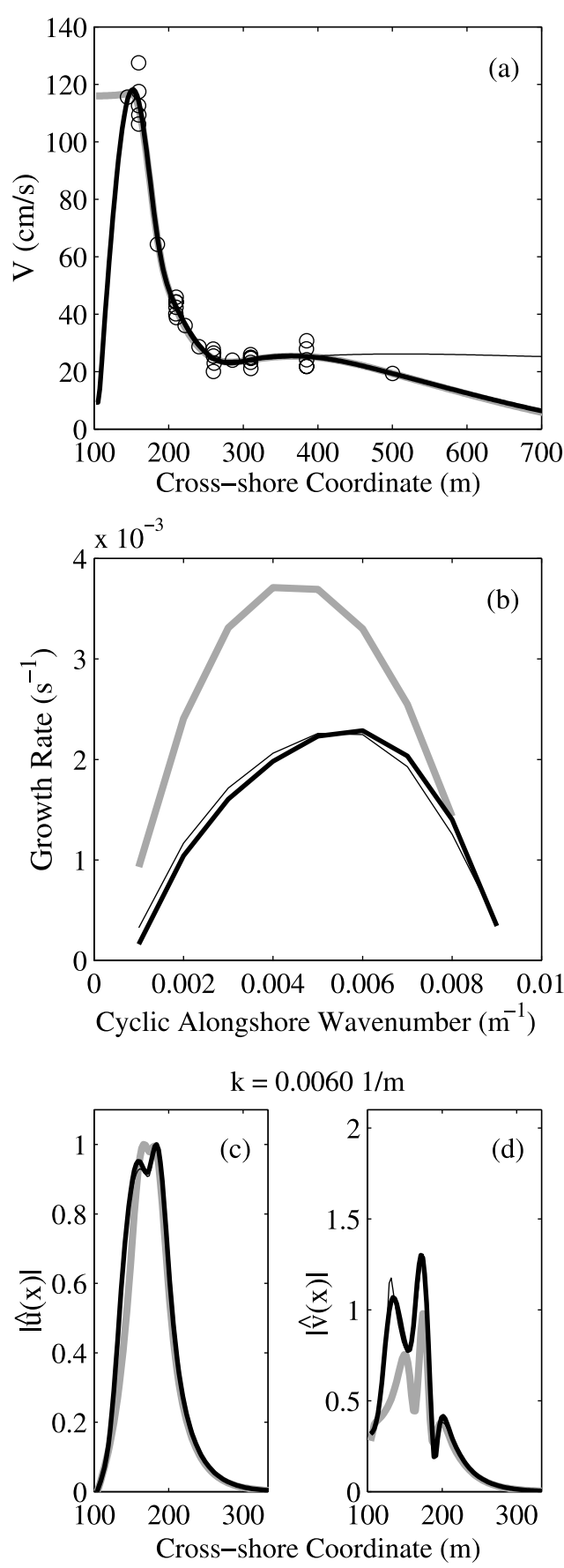

Figure D1. (a) Spline fit $V(x)$ versus the cross-shore coordinate on 2 October. The three spline fits shown differ primarily at coordinates less than $180 \mathrm{~m}$ (the thick shaded curve is nearly horizontal at $118 \mathrm{~cm} \mathrm{~s}^{-1}$ ) and greater than $400 \mathrm{~m}$ (the thin curve is above the thick curve). (b) Growth rate versus alongshore wave number for the unstable modes of each spline fit. The line types in Figure D1b correspond to the spline fits in Figure D1a. The modulus of the eigenfunctions for (c) cross-shore $\hat{u}$ and (d) alongshore $\hat{v}$ velocities of the unstable mode with $k=0.006 \mathrm{~m}^{-1}$ versus the cross-shore coordinate. 
[1996]. A second-order finite difference solution was found at each alongshore wave number $\kappa$ for a system of algebraic equations of the form

$$
A \hat{\psi}=c B \hat{\psi}
$$

with boundary conditions $\hat{\psi}(k, x)=0$ (i.e., zero cross-shore transport) at the shoreline and offshore boundaries. The 600-m-wide cross-shore domain was spanned with 241 grid points $(d x=2.5 \mathrm{~m})$. At each $\kappa$, there are 239 eigenvalues $c$ and eigenvectors $\hat{\psi}(k, x)$. Spurious numerical modes that depend on the gridding and do not approximate solutions of the continuous equation can occur, but the properties of the modes discussed here are insensitive to increasing the number of grid points.

[49] Changing the shoreline boundary condition from $V=0$ to the value of $V$ observed at the most onshore current meter (thick grey curve near $V \approx 120 \mathrm{~cm} \mathrm{~s}^{-1}$ in Figure D1a), increases the maximum growth rate by $\approx 50 \%$, but only weakly effects the range of unstable wave numbers (Figure D1b) and $C_{\text {unstable }}$ (not shown). The shapes of the $\hat{u}$ (proportional to the eigenfunction $\hat{\psi}$ ) are insensitive to this change in boundary conditions, whereas $\hat{v}$ (proportional to $\hat{\psi}_{x}$ ) are altered near the shoreline (Figures D1c and D1d). Changing the seaward boundary condition, from $V=0$ far offshore to the value of $V$ observed at the farthest offshore array (thin solid curve in Figure D1a), produces only small changes in the unstable modes (compare thick with thin solid lines in Figures D1b-D1d).

[50] Acknowledgments. This research was supported by the Office of Naval Research, the National Ocean Partnership Program and the National Science Foundation. The nearshore arrays were deployed and maintained by staff from the Center for Coastal Studies, Scripps Institution of Oceanography. Staff from the U.S. Army Corps of Engineers Field Research Facility, Duck, North Carolina, provided processed survey data from their amphibious vehicle, data from their pressure array in 8-m water depth, and excellent logistical support. Britt Raubenheimer and Falk Feddersen contributed to the field experiment. Falk Feddersen also provided the code for the numerical simulations shown in Figure 11. Alex Sheremet provided the code for finding the edge wave dispersion relation.

\section{References}

Allen, J. S., P. A. Newberger, and R. A. Holman (1996), Nonlinear shear instabilities of alongshore currents on plane beaches, J. Fluid. Mech., $310,181-213$.

Baquerizo, A., M. Caballeria, M. A. Losada, and A. Falqués (2001), Frontshear and backshear instabilities of the mean longshore current, J. Geophys. Res., 106, 16,997-17,011.

Bowen, A. J., and R. A. Holman (1989), Shear instabilities of the mean longshore current: 1 . Theory, J. Geophys. Res., 94, 18,023-18,030.

de Boor, C. (1978), A Practical Guide to Splines, 392 pp., Springer-Verlag, New York.

Dodd, N., and E. B. Thornton (1990), Growth and energetics of shear waves in the nearshore, J. Geophys. Res., 95, 16,075-16,083.

Dodd, N., J. Oltman-Shay, and E. B. Thornton (1992), Shear instabilities in the longshore current: A comparison of observations and theory, J. Phys. Oceanogr., 22, 62-82.
Dodd, N., V. Iranzo, and A. Reniers (2000), Shear instabilities of wavedriven alongshore currents, Rev. Geophys., 38, 437-463.

Elgar, S., R. T. Guza, W. C. O'Reilly, B. Raubenheimer, and T. H. C. Herbers (2001), Wave energy and direction observed near a pier, J. Waterw. Port Coastal Ocean Eng., 127, 2-6.

Herbers, T. H. C., S. Elgar, and R. T. Guza (1995), Generation and propagation of infragravity waves, J. Geophys. Res., 100, 24,863-24,872.

Herbers, T. H. C., M. Orzech, S. Elgar, and R. T. Guza (2003), Shoaling transformation of wave frequency-directional spectra, J. Geophys. Res., 108(C1), 3013, doi:10.1029/2001JC001304.

Horel, J. D. (1984), Complex principal component analysis: Theory and examples, J. Clim. Appl. Meteorol., 23, 1660-1673.

Howd, P. A., J. Oltman-Shay, and R. A. Holman (1991), Wave variance partitioning in the trough of a barred beach, J. Geophys. Res., 96, $12,781-12,795$.

Howd, P. A., A. J. Bowen, and R. A. Holman (1992), Edge waves in the presence of strong longshore currents, J. Geophys. Res., 97, 11,35711,371 .

Lentz, S., S. Elgar, and R. T. Guza (2003), Observations of the flow field near the nose of a buoyant coastal current, J. Phys. Oceanogr., 33, $933-$ 943.

Lippmann, T. C., T. H. C. Herbers, and E. B. Thornton (1999), Gravity and shear wave contributions to nearshore infragravity motions, J. Phys. Oceanogr., 29, 231-239.

Long, R., and J. Oltman-Shay (1991), Directional characteristics of waves in shallow water, Tech. Rep. CERC-91-1, U.S. Army Eng. Waterw. Exp. Stn., Vicksburg, Miss.

Miles, J. R., P. E. Russell, B. G. Ruessink, and D. A. Huntley (2000), Field observations of the effect of shear waves on sediment suspension and transport, Cont. Shelf Res., 22, 657-681.

Munk, W., F. Snodgrass, and F. Gilbert (1964), Long waves on the continental shelf: An experiment to separate trapped and leaky modes, J. Fluid. Mech., 20, 529-554.

Noyes, T. J. (2002), Field observations of shear waves, Ph.D. thesis, Scripps Inst. of Oceanogr., La Jolla, Calif.

Noyes, T. J., R. T. Guza, S. Elgar, and T. H. C. Herbers (2002), Comparison of methods for estimating nearshore shear wave variance, J. Atmos. Oceanic Technol., 19, 136-143.

Oltman-Shay, J., P. Howd, and W. Birkemeier (1989), Shear instabilities of the mean longshore current: 2. Field observations, J. Geophys. Res., 94, $18,031-18,042$.

Özkan-Haller, H. T., and J. T. Kirby (1999), Nonlinear evolution of shear instabilities of the longshore current: A comparison of observation and computations, J. Geophys. Res., 104, 25,953-25,984.

Pawka, S. (1983), Island shadows in wave directional spectra, J. Geophys. Res., 88, 2579-2591.

Pedlovsky, J., and J. Thomson (2003), Baroclinic Instability of time dependent currents, J. Fluid. Mech., 40, 189-215.

Slinn, D. N., J. S. Allen, P. A. Newberger, and R. A. Holman (1998), Nonlinear shear instabilities of alongshore currents over barred beaches, J. Geophys. Res., 103, 18,357-18,379.

Thornton, E. B., and C. S. Kim (1993), Longshore current and wave height modulation at tidal frequency inside the surf zone, J. Geophys. Res., 98, $16,509-16,519$

S. Elgar, Woods Hole Oceanographic Institution, Woods Hole, MA 02543, USA. (elgar@whoi.edu)

R. T. Guza and T. J. Noyes, Integrative Oceanography Division, Scripps Institution of Oceanography, 9500 Gilman Dr. 0209, La Jolla, CA 92093 0209, USA. (jnoyes@coast.ucsd.edu)

T. H. C. Herbers, Department of Oceanography, Code OC/He, Naval Postgraduate School, Monterey, CA 93943-5122, USA. (herbers@oc.nps. navy.mil) 